\begin{abstract}
DETECTING AN INVASIVE SHRUB IN DECIDUOUS FOREST UNDERSTORIES USING REMOTE SENSING
\end{abstract}

by Bryan N. Wilfong

Remote sensing has been used to directly detect and map invasive plants, but has not been used for forest understory invaders because they are obscured by a canopy. However, if the invasive species has a leaf phenology distinct from native forest species, then temporal opportunities exist to detect the invasive. Lonicera maackii, an Asian shrub that invades North American forests, expands leaves earlier and retains leaves later than native woody species. I explored whether Landsat $5 \mathrm{TM}$ and Landsat $7 \mathrm{ETM}+$ imagery could predict L. maackii cover across woodlots in Darke and Preble Counties in south western Ohio and Wayne County, Indiana. The best predictor of L. maackii cover was Normalized Difference Vegetation Index (NDVI) from November 2005 , with a quadratic function providing a better fit $\left(\mathrm{R}^{2}=0.75\right)$ than a linear function. This predictive model was verified with 15 other woodlots. With refinement, this approach can map understory invasion by L. maackii. 


\title{
DETECTING AN INVASIVE SHRUB IN DECIDUOUS FOREST UNDERSTORIES USING REMOTE SENSING
}

\author{
A Thesis \\ Submitted to the \\ Faculty of Miami University \\ in partial fulfillment of \\ the requirements for the degree of \\ Masters of Environmental Science \\ Institute of Environmental Science \\ by \\ Bryan N. Wilfong \\ Miami University \\ Oxford, $\mathrm{OH}$ \\ 2008
}

Advisor

(David L. Gorchov)

Reader

(Mary C. Henry)

Reader

(Jerry E. Green) 


\section{Contents}

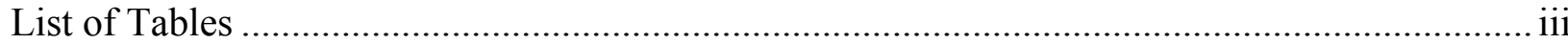

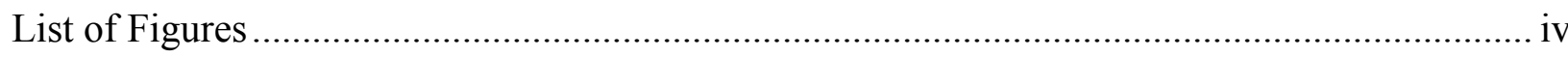

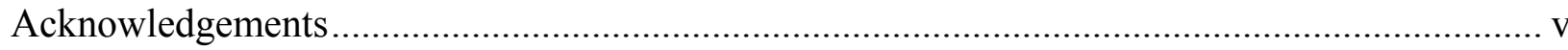

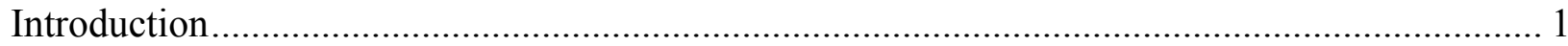

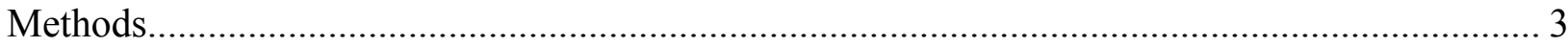

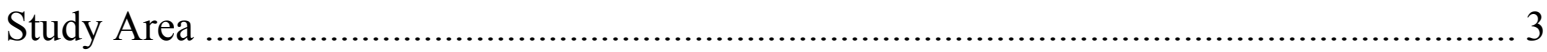

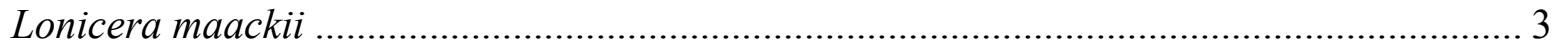

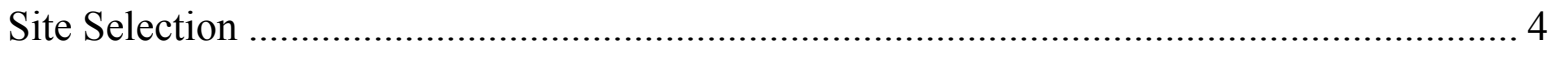

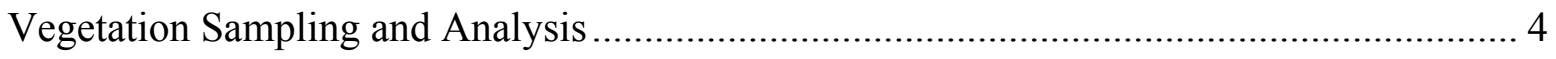

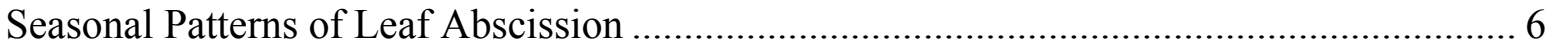

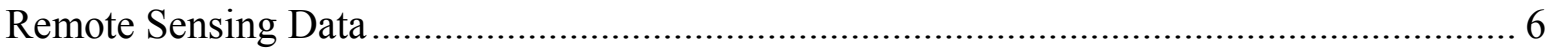

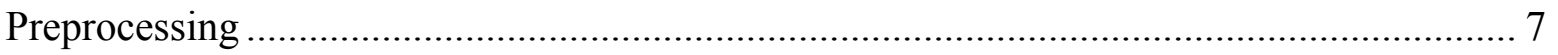

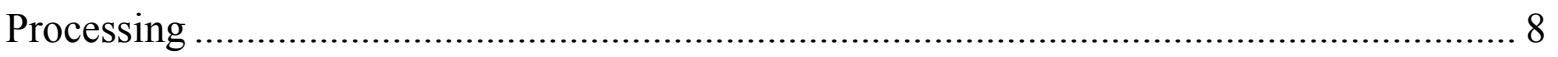

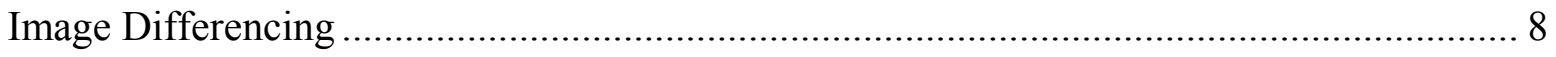

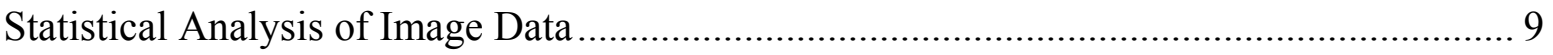

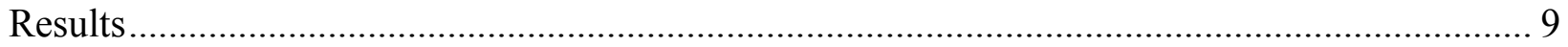

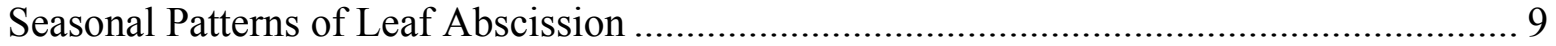

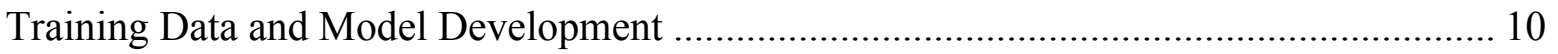

Regression of L. maackii cover on spectral data................................................... 10

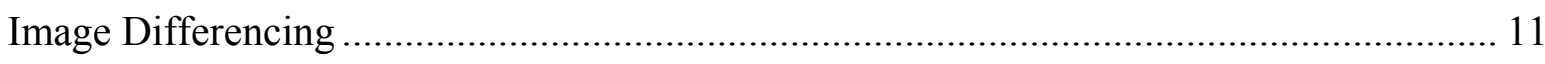

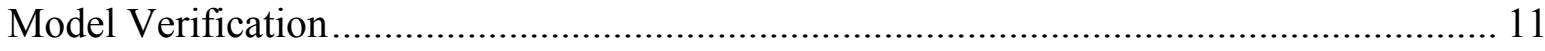

Influence of Other Variables on Model Performance ......................................................... 12

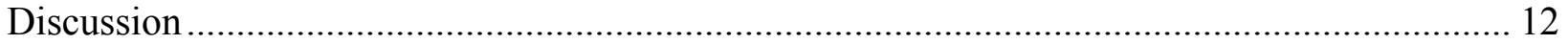

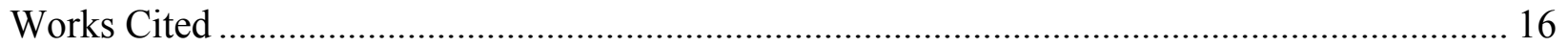

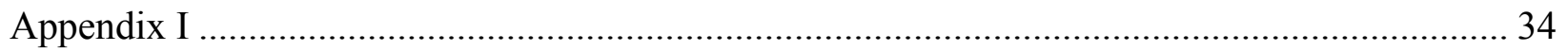

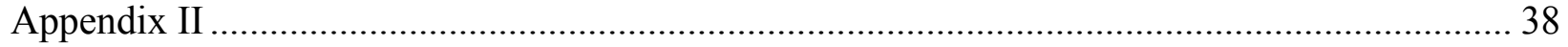

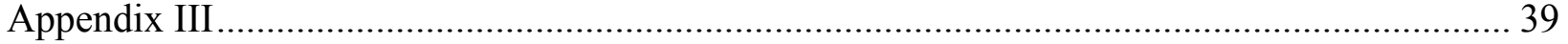




\section{List of Tables}

Table 1 Lonicera maackii cover classes and number of ground plots within each level of L. maackii cover.

Table 2 Spectral and spatial characteristics of Landsat 5 TM and Landsat 7 ETM+ where IR=infra red (modified from Jensen 2007).

Table 3 Conversion equations for Landsat 5 image DN values to Landsat 7 equivalents (USGS 2001).

Table 4 Image and band specific equation values for DN to radiance conversion...... 23

Table 5 Individual COST model equations for each band and image date.

Table 6 Pearson's correlation coefficients for the four SVIs most strongly correlated with amount of L. maackii cover for the November 12, 2005 training data $(\mathrm{N}=$ $35)$.

Table $7 \mathrm{R}^{2}$ and $\mathrm{p}$-values from the least squares regression analysis of the November 12, 2005 training data $(\mathrm{N}=35)$ where L. maackii cover was regressed on individual SVI and reflectance band values.

Table $8 \mathrm{R}^{2}$ and $\mathrm{p}$-values from linear regression analyses of various data transformations applied to the November 12, 2005 training data $(\mathrm{N}=35)$, where L. maackii was regressed on NDVI.

Table 9 Comparison of RMSE, $\mathrm{R}^{2}$, and $\mathrm{p}$-values of the OLS regression model to the quadratic polynomial regression model for the November 12, 2005 training data $(\mathrm{N}=35)$ where $L$. maackii cover was regressed on NDVI.

Table 10 Stepwise multiple regression models and analysis values for the November 12, 2005 training data $(\mathrm{N}=35)$ where $\mathrm{Y}=$ L. maackii percent cover and the various SVIs and reflectance bands are the dependent variables. Mallows $\mathrm{C}_{(\mathrm{p})}$ statistic is related to the mean square error of a fitted value and identifies parsimonious models with good predictive power. The better model is one where Mallows' Cp is small and close to the number of predictors in the model plus the constant $(\mathrm{p})$.

Table 11 Results of the linear and quadratic polynomial regression analyses of $L$. maackii on the top performing SVI from the January 28, 2002 minus November 12, 2005 training data values $(\mathrm{N}=35)$ and the June 11, 2007 minus November 12, 2005 training data values

Table $12 \mathrm{R}^{2}$ and $\mathrm{p}$-values from the regression analysis of the November 12, 2005 verification data $(\mathrm{N}=15)(\mathrm{Y}=$ observed $\mathrm{L}$. maackii cover, $\mathrm{X}=$ the predicted $L$. maackii cover). 


\section{List of Figures}

Figure 1 Distribution of plots represented with black circles within the study area. The inset window displays the location and extent of Landsat Path 20 Row 32 coverage and the location of the study area within that extent.

Figure 2 Polygons drawn in ArcMap over suitable woodlots using mosaiced DOQQs.

Figure 3 Fall 2006 canopy and shrub layer in sites with high L. maackii abundance (ERC and Kramer) versus sites with no L. maackii presence (Sugarbush and Bigwoods), where solid line is shrub layer and dashed line is canopy. 28

Figure 4 Fall 2007 canopy and shrub layer in sites with high L. maackii abundance (ERC and Kramer) versus sites with no L. maackii presence (Sugarbush and Bigwoods), where solid line is shrub layer and dashed line is canopy.

Figure 5 Linear regression of L. maackii cover on NDVI of the November 12, 2005 training data. Different color circles distinguish plots with different graminoid cover $($ high $=$ black, medium $=$ grey, and low $=$ white $)$

Figure 6 Quadratic polynomial regression of L. maackii cover on NDVI of the November 12, 2005 training data. Different color circles distinguish plots with different graminoid cover $($ high $=$ black, medium $=$ grey, and low $=$ white $)$.

Figure 7 Linear regression of observed L. maackii cover on predicted L. maackii cover values. Predicted values were calculated from the November verification data using the quadratic polynomial regression model of NDVI. Different color circles distinguish plots

Figure 8 Linear regression of observed L. maackii cover on predicted L. maackii cover values. Predicted values were calculated from the November 12, 2005 verification data using the linear regression model of NDVI. Different color circles distinguish plots with

Figure 9 Linear regression of L. maackii cover on NDVI using the November training data. Different color circles distinguish plots with differences in disturbance (evident disturbance $=$ black and no apparent disturbance $=$ white $).$

Figure 10 Quadratic regression of L. maackii cover on NDVI using the November training data. Different color circles distinguish plots with differences in disturbance (evident disturbance $=$ black and no apparent disturbance $=$ white).

Figure 11 Linear regression of L. maackii cover on NDVI using the November training data. Different color circles distinguish between plots with Quercus species and F. grandifolia comprising $>20 \%$ of basal area ( black $=$ high Quercus and F. grandifolia and white $=$ low Quercus and F. grandifolia)

Figure 12 Quadratic regression of L. maackii cover on NDVI using the November training data. Different color circles distinguish between plots with Quercus species and $F$. grandifolia comprising $>20 \%$ of basal area (black $=$ high Quercus and F. grandifolia and white $=$ low Quercus and F. grandifolia). 


\section{Acknowledgements}

I thank my committee members for their insight and assistance in the completion of this thesis. Deep appreciation is extended to David Gorchov, my thesis advisor, for improving my writing skills, furthering my knowledge of ecology and methods of statistical analysis, and his patience. Thanks also to my parents, Bea and Sam Wilfong, my brother, Ryan, and my great friend, Laura Spadaro, for providing much support and encouragement.

This research was supported in part by grants from U.S. Department of Agriculture National Research Initiative Competitive Grants Program to D.L. Gorchov, M.C. Henry, and Oscar J. Rocha and the National Garden Club of Ohio to B. N. Wilfong. Further assistance was provided by the Department of Botany and the Institute of Environmental Science at Miami University. Thanks are given to the Miami University Ecology Research Center, the Ohio Department of Natural Resources Division of Natural Areas and Preserves, and those property owners in Darke and Preble Counties, $\mathrm{OH}$ and Wayne County, IN that granted access to their woodlots. 


\section{Introduction}

Invasion of native ecosystems by exotic species is a major threat to global biodiversity and is considered a significant cause of ecological change at multiple scales (Hooper et al. 2005). In the United States, invasion by exotic species has been identified as a significant threat to the survival of indigenous species (Wilcove et al. 1998). Invasive exotic species are estimated to cost the U.S. economy over $\$ 137$ billion per year in damages and control costs (Pimentel et al. 2000). Within the U.S. it is estimated that exotic plants invade 700,000 hectares of wildlife habitat annually and that 5,000 exotic plant species have become established in native ecosystems (Pimentel et al. 2000).

Exotic plants typically exert negative impacts on invaded systems and significantly alter ecosystem processes, plant community composition, and influence the structure of trophic levels (Vitousek 1990; Eiswerth and Johnson 2002; Levine et al. 2003; Chornesky et al. 2005). The problems associated with invasive species are expected to worsen as the anthropogenic factors that have greatly accelerated the rate of exotic propagule introduction and the disturbance activities that facilitate invasion of native ecosystems are increasing (Eiswerth and Johnson 2002; Levine et al. 2003). In recognition of the deleterious effects of invasive species, research on the dynamics of ecosystem invasion and management efforts to control the spread of exotic species have been identified as priorities at the global and national level (Andersen et al. 2004; Leung et al. 2005).

Information about the distribution of exotic plant populations is essential in the formulation of effective ecological conservation policies, the development of management and control efforts, and to gain insight into the dynamics of ecosystem invasion (Byers et al. 2001; Eiswerth and Johnson 2002; Rew et al. 2005; Bradley and Mustard 2006). Quantification of the spatial distribution of exotic plants within an invaded system is the primary parameter used to evaluate the efficacy of control efforts (Cooksey and Sheley 1997). Information about the spatial distribution of invasive plant populations improves the accuracy of attempts to measure the economic and ecological impacts of invasive species, informs predictions about future population densities, and likely pathways of dispersal (Parker et al. 1999; Andersen et al. 2004; Cohen and Goward 2004). Furthermore, information on the current and historical distributions of invasive plant populations across the landscape can provide insight into mechanisms that facilitate invasion. 
Those involved in the study and control of invasive species expend considerable resources to gather information about the current spatial distribution and population abundances of invasive species (Byers et al. 2001; Rew et al. 2005; Deckers et al. 2005). Traditional groundbased methods for gathering this information are high in resource costs; thus, research and management activities are often constrained by financial and/or logistical costs (Caughlan and Oakley 2001; Anderson et al. 2003; Lawrence et al. 2006; Rew et al. 2005). Remote sensing can provide information on the spatial and temporal distributions of plant populations (Kerr and Ostrovsky 2003; Shaw 2005) in an efficient and cost-effective way (Rew et al. 2005; Patil et al. 2001).

For example, the ability to accurately identify the spatial distribution of an invasive exotic plant species would enhance the efficacy of control and management efforts by enabling land managers to more accurately direct eradication programs, develop better predictive models about future dispersal, and coordinate management programs across multiple scales. Furthermore, enhancing our ability to detect plant communities that have been invaded by an exotic species and those that have not will aid research into what characteristics make ecosystems susceptible to invasion by exotic species. The identification of such characteristics has been identified as being of critical importance in the control of invasive species and in mitigating the impacts of exotic species invasion (Hobbs and Humphries 1995).

Remote sensing has been used to detect and map the distribution of invasive plants in a variety of ecosystems where the invasive was not beneath a canopy. Examples include semi-arid grasslands (Bradley and Mustard 2005; Lass et al. 2005; Peterson 2005), wetlands (Pengra et al. 2007; Laba et al. 2008) and riparian communities (Hamada et al. 2007; Noonan and Chafer 2007). Forest understory invaders are difficult to detect because they are obscured by the canopy. However, if the invasive species has a leaf phenology that differs from native forest species, then temporal opportunities may exist to detect the invader. Exotic shrubs, such as Lonicera maackii, often leaf out earlier in the spring and retain leaves longer in the fall than native deciduous species (Trisel and Gorchov 1994). As a result of this phenological difference remote sensing platforms should be able to detect such invasive shrubs in forest understories in the early spring and late fall when native deciduous species are leafless.

Phenological differences have been used in numerous studies to derive ecological information from remote sensing data. Differences in phenology between native species and the 
invasive grass Bromus tectorum were exploited to map the distribution of B. tectorum using Landsat 5 Thematic Mapper (TM) and Landsat 7 Enhanced Thematic Mapper Plus (ETM+) data (Bradley and Mustard 2005; Peterson 2005). Resasco et al. (2007) demonstrated that it might be possible to use Landsat images and differences in leaf phenology to identify dissimilarity in spectral reflectance values of stands with $L$. maackii versus non-invaded stands in images captured after forest canopy leaves had fallen.

The objective of this study is to test the hypothesis that differences in leaf phenology between $L$. maackii and native tree species can be used to estimate the cover abundance of $L$. maackii in forest understories through the analysis of remote sensing data.

\section{Methods}

\section{Study Area}

The study area was approximately 1,200 $\mathrm{km}^{2}$ (Figure 1) in Darke and Preble Counties in southwestern Ohio and neighboring Wayne County, Indiana. The landscape of the study area is a patchwork of small woodlots with varying degrees of connectivity surrounded by agricultural fields, farm houses, and small towns. Darke County was identified by Bartuzevige et al. (2006) as an area that is on the front of an advancing L. maackii invasion, where forest patches exhibit a range of L. maackii abundance.

\section{Lonicera maackii}

Lonicera maackii is a perennial shrub originating in northeastern Asia. It was introduced into the U.S. in 1898 and has been widely cultivated for a variety of purposes (Luken and Thieret 1995). The plant escaped cultivation and has now established naturalized populations in at least 24 eastern states (Trisel and Grochov 1994) and 35 Ohio counties (Trisel 1997). Propagule pressure of L. maackii is high, as the shrub's fruit has been incorporated into the diets of numerous avian species that disperse viable L. maackii seeds to habitats suitable for the shrub's establishment (Batuszevige and Gorchov 2006).

Lonicera maackii impacts forest ecosystems at multiple levels and the shrub exhibits the potential to alter natural patterns of forest succession and influence trophic structure. Lonicera maackii reduces growth and fecundity of native annual and perennial herbs due to competitive effects (Gould and Gorchov 2000; Miller and Gorchov 2004), fecundity of annual and biennial herbs from potential allelopathic effects (Dorning and Cipollini 2006; Cipollini et al. 2008), and 
survival and growth of native tree seedlings (Gorchov and Trisel 2003; Hartman and McCarthy 2004). Under L. maackii canopies the species richness and abundance of native herbs and tree seedlings are reduced (Collier et al. 2002). In forest stands with established populations of $L$. maackii overstory trees have significantly lower rates of radial growth (Hartman and McCarthy 2007). Comparisons among stands with differing levels of L. maackii abundance revealed a negative relationship between L. maackii density and the density of Acer saccharum (Hutchinson and Vankat 1997). Lonicera maackii also has the potential to influence the trophic structure of invaded ecosystems, since songbird nests in L. maackii suffered higher predation than nests constructed in native species (Schmidt and Whelan 1999).

\section{Site Selection}

I located woodlots of sufficient spatial extent using ArcMap and digital orthophotos (DOQQs) of the study area, obtained from the Darke County Geographic Information Office and the Preble County Planning Department. Woodlots greater than $120 \mathrm{~m}$ by $120 \mathrm{~m}$ in extent were identified for the location of a $100 \mathrm{~m}$ by $100 \mathrm{~m}$ study plot with at least a $15 \mathrm{~m}$ buffer on all sides. The perimeters of woodlots that met the size requirement (Figure 2) were digitized and saved as shapefiles with a projection in UTM WGS 1984 Zone 16 North. Pathfinder Office was used to load the shapefiles into a handheld Trimble GPS unit with sub-meter accuracy.

\section{Vegetation Sampling and Analysis}

The woodlot polygon layer was used in conjunction with the GPS unit to identify woodlots suitable for the placement of ground plots (GPs). Once permission was granted by property owners, potential woodlots were reconnoitered and those found suitable for inclusion were sampled. An attempt was made to select woodlots that had similar stand characteristics (e.g. basal area, species composition), relatively flat topography, and a range of L. maackii cover densities. However, great difficulty was encountered in finding woodlots with medium to high densities of L. maackii invasion; as a result it was not always possible to place GPs in woodlots that had similar stand characteristics.

Once a woodlot was selected for the placement of a GP, I selected an anchor point for the start of the mainline transect that ensured all transect lines remained within the woodlot and did not extend into the $15 \mathrm{~m}$ edge buffer. The woodlot polygon layer and the Trimble GPS unit were 
used to aid in the placement of the anchor point and to determine the azimuths for the mainline and line intercepts.

A total of 50 GPs were obtained across of range of L. maackii cover (Appendix III). In each GP I established one $100 \mathrm{~m}$ baseline transect with four $100 \mathrm{~m}$ parallel line intercept transects spaced $25 \mathrm{~m}$ apart. The four parallel transects served a dual purpose as line intercepts to quantify L. maackii cover and as anchor lines for point-quarter plots (PQPs). Whenever a L. maackii individual intercepted a vertical projection of a line intercept transect, the start and end point of the interception was recorded to the nearest $\mathrm{cm}$. These distances were then summed to calculate the total portion of the 4 lines covered by L. maackii. The GPS unit was used to collect the geographic coordinates of the anchor and end points of each main transect line.

The PQPs were used to collect basic forest stand community characteristics. There were 4 PQPs per transect line for a total of 16 PQPs per GP. The first PQP was located randomly within the first $25 \mathrm{~m}$, with the other three PQPs spaced at $25 \mathrm{~m}$ intervals. The nearest tree $\geq$ $10 \mathrm{~cm}$ in diameter at breast height $(\mathrm{dbh})$ in each quadrant of the PQP was identified to species and its dbh and distance from the PQP center recorded. I also recorded large treefall gaps, topographical variation, graminoid cover and indications of observable disturbance such as recent timber harvests, livestock grazing, vehicle trails, or trash dumps. Data from the PQPs were used to calculate stand density, stand basal area, and total basal area, as well as absolute basal area, relative basal area, absolute density, and relative density of individual tree species, as described by Smith and Smith (2001).

Graminoid cover abundances for each woodlot were recorded in three categories; high, medium, and low. Low cover plots had very little graminoid cover in the understory. Medium cover plots had a patchy distribution of dense graminoid cover (e.g. in canopy gaps and on roads/skid trails). High cover plots were those woodlots that had substantial amounts of graminoid cover throughout the understory.

GPs were divided into eight groups based upon the percent L. maackii cover observed (Table 1). In each of these groupings approximately two-thirds were used as training and onethird as verification data. The random number generating function within Excel was used to assign a random value to each letter and the plots with highest randomly generated values in each group were placed in the verification pool. 


\section{Seasonal Patterns of Leaf Abscission}

In order to confirm the differences in phenology between native species and L. maackii and to identify the optimal dates for image acquisition it was necessary to quantify fall leaf senescence. Sampling was conducted in two plots with high levels of L. maackii abundance (the Ecology Research Center (ERC) of Miami University with 57\% L. maackii cover and Kramer Woods, Miami University Natural Areas with 37\% L. maackii cover) and two plots with no L. maackii (the Sugarbush and Bigwoods stands in Hueston Woods State Park) all plots are in Butler County, Ohio.

Sample plots consisted of four 50m transect lines that were spaced $25 \mathrm{~m}$ apart. Pin flags were spaced every $5 \mathrm{~m}$ along transects. In the 2006 sampling 54 sample points per plot were placed and in the 2007 sampling 50 sample points were placed. The corner coordinates of the plots established by Resasco et al. (2007) were used to establish the anchor points for line transects.

Measurements of the forest canopy and the shrub layer were taken with a vertical densitometer using the procedure described by Stumpf (1993). Overstory canopy measurements were taken approximately $3.5 \mathrm{~m}$ from the ground surface through the use of a stepladder. Measurements of the understory were from the same position, but with the vertical densitometer pointing downwards. In 2006, sampling was begun on October $21^{\text {st }}$ and ended on December $2^{\text {nd }}$ with measurements collected every seven days. In 2007, canopy sampling was begun September $9^{\text {th }}$ and finished December $1^{\text {st }}$ with measurements collected every seven days.

\section{Remote Sensing Data}

I used images from Landsat Path 20 Row 32. Two images from the Landsat 5 Thematic Mapper (TM) platform, one captured on June 11, 2007 and the other on November 12, 2005 for full leaf and canopy leaf off, respectively. A Landsat 7 Enhanced Thematic Mapper Plus (ETM+) image captured on January 28, 2002 was used for canopy and understory leaf off. This combination was necessary to find cloud free and snow free images of the desired dates, and in an effort to use the most current and complete images available. Georectified images for these three dates were acquired from OhioView.org and the metadata for each image was obtained from USGS's EarthExplorer website (http://edcsns17.cr.usgs.gov/EarthExplorer/).

The June image established a baseline for green biomass when both the overstory and understory are photosynthetically active. The November image was collected when overstory 
leaves had senesced and the majority had abscised while in the understory L. maackii still had green leaves. This assumption was based on the canopy sampling conducted in the fall of 2006, observed patterns of fall leaf abscision collected by the Ohio Department of Natural Resources (available at http://www.dnr.state.oh.us), and Trisel and Gorchov (1994). The January image would have been captured when deciduous plants in the overstory and understory were no longer photosynthetically active and virtually devoid of leaves. All preprocessing and processing of the remote sensing data were performed using Leica Geosystems' ERDAS Imagine software.

\section{Preprocessing}

OhioView.org provides Landsat 5 and Landsat 7 data in a georectified Tagged Image File Format (tiff) with each spectral band available in separate tiff files. For the purposes of this study Landsat 5 and Landsat 7 bands one through five and seven were used (Table 2). Landsat 5 and Landsat 7 store image data in a digital number (DN) format which is a measure of at-satellite radiance. It was necessary to convert the Landsat 5 images into Landsat 7 equivalents, as these values are not directly comparable between satellite platforms. The conversion of DN values was performed using the conversion equation (Table 3) developed by the USGS (2001) and the Imagine Model function.

DN values must be converted to equivalent at-satellite radiance values for further processing and this is accomplished through the use of the equation:

$$
L_{\lambda}=L_{\min \lambda}+\frac{\left(L_{\max \lambda}-L_{\min \lambda}\right)}{255} \times D N
$$

$L_{\min \lambda}$ and $L_{\max \lambda}$ are standard values derived from the Landsat7 ETM+ radiometric calibration curve and represent the post-calibration dynamic ranges where the $L_{\min \lambda}$ value corresponds to the minimum DN value of zero and $L_{\max \lambda}$ corresponds to the maximum DN value of 255 (Chander et al. 2007). The individual band equations for each image are in Table 4.

The next phase of image preprocessing involves the conversion of radiance values to reflectance values and the correction of atmospheric effects on the reflectance values. The radiance values must be converted to reflectance before analysis of ecological parameters can be performed (Jensen 2007) and radiometric correction is necessary because at-satellite radiance is affected by the scattering, absorption, and refraction of light in the atmosphere (Chavez 1996). The cosine approximation model (COST) developed by Chavez (1996) was used to correct for atmospheric effects using the following formula: 


$$
\text { Reflectance }=\frac{\pi \times\left(\text { Image }-L_{\text {haze }}\right) \times d^{2}}{\operatorname{Esun}(\cos Z)}
$$

Image specific models using the appropriate values for each image date and band (Table 5) were created using the Imagine Modeler tool. Once processed, each image's radiance values were transformed to reflectance and atmospheric effects on reflectance were reduced.

\section{Processing}

Image values were transformed to obtain spectral vegetation indices (SVIs), which are combinations of spectral information from multiple bands that produce an image which exhibits increased sensitivity to plant biophysical variables while external and internal effects (e.g. background soil reflectance) are reduced (Jensen 2007). It was predicted that in the November image there would be a positive correlation between SVI values and L. maackii abundance; more specifically, woodlots with a high abundance of L. maackii in the understory would exhibit higher SVI values compared to woodlots with low to no L. maackii presence.

Seven SVIs image transformations were performed: 1) Normalized Difference Vegetation Index (NDVI) (Rouse et al. 1974), 2) Enhanced Vegetation Index (EVI) (Huete et al. 1997), 3) Simple Ratio (SR) (Birth and McVey 1968; Cohen 1991), 4) Kauth-Thomas Transformation or Tasseled Cap (TCap) (Kauth and Thomas 1976; Crist and Cicone 1984; Huang et al. 2002), 5) Visible Atmospherically Resistant Index (VARI) (Gitelson et al. 2002), 6) Soil Adjusted Vegetation Index (SAVI) (Huete 1988), and 7) Normalized Difference Moisture Index (NDMI) (Hardisky et al. 1983).

Following image transformation, ArcMap 9.2 was used to extract the mean values for pixels that fell within the delineated plots. ArcCatalog was used to create two separate shapefiles, one containing the verification plots and the other containing training plots. Value extraction was accomplished through the use of the Spatial Analyst tool within ArcMap. Mean values for each plot were extracted from all SVI images, as well as the six reflectance bands (RB) for each image date.

\section{Image Differencing}

Image differencing was performed with the expectation that emphasizing seasonal changes in L. maackii cover could enhance the ability to detect L. maackii cover. For example, image differencing of Landsat TM data has been used to detect changes in vegetative cover due 
to anthropogenic disturbance (Norberg and Evertson 2003). Imagine was used to subtract the November image from the June image and the January image from the November image. This process was repeated for each SVI image transformation and for all six reflectance images. Plot pixel values were extracted from these images using the Spatial Analyst tool in ArcMap.

\section{Statistical Analysis of Image Data}

Correlation and regression analyses were performed using SAS 9.1 to evaluate the ability of the different SVIs to accurately predict L. maackii cover. The training data was used to develop models that predict L. maackii cover. Three different regression methods were utilized: ordinary least squares linear, multiple predictors stepwise, and quadratic polynomial. The November 12, 2005 training data was used to develop the best model for predicting L. maackii. In all model iterations L. maackii cover served as the response variable and the extracted pixel values of the different SVI transformations and individual reflectance images were the predictor variables. Correlation and regression analyses were also performed on the PQP data to determine if any quantified woodlot parameters exerted a detectable influence on reflectance values.

The verification data was used to test the validity of the top performing regression models created with the training data. The extracted pixel values for the 15 verification plots were used to generate predicted L. maackii cover based on each model. The observed L. maackii cover values were then regressed against the predicted L. maackii cover to evaluate model performance.

\section{Results}

\section{Seasonal Patterns of Leaf Abscission}

The results of the 2006 ( Figure 3) and 2007 (Figure 4) canopy sampling confirm that there was approximately a four week period in which the leaves of the native deciduous trees had abscised while those of L. maackii were still green. In 2006 the heavily L. maackii invaded ERC and Kramer Woods stands had a significant amount of green leaves in the shrub layer in November, while their main canopies were mostly devoid of leaves. Whereas, the canopies and shrub layers of the Sugarbush and Bigwoods stands, with no L. maackii present, exhibited a 
virtual absence of green leaves. This condition persisted from approximately November 04 to November 30, when L. maackii leaves abscised.

In 2007 the temporal difference in leaf abscission between native canopy and exotic shrub species (Figure 3) was repeated; however, abscission dates were later than in 2006 . In 2007 the optimal time to detect L. maackii in the understory using satellite imagery began on November 22, 18 days later than in 2006.

\section{Training Data and Model Development}

A correlation analysis of SVIs and reflectance bands revealed a high degree of correlation between virtually all indices and reflectance bands, while no significant correlations were found to exist between the remote sensing data for any of the three dates and stand density or stand basal area (Appendix I). L. maackii cover was correlated with four SVIs, with NDVI having the highest correlation value (Table 6). No other SVI or individual reflectance band had a correlation value with L. maackii greater than 0.5 (Appendix I).

\section{Regression of L. maackii cover on spectral data}

Univariant linear regression from the November 12, 2005 image revealed that NDVI and SR were the best predictors of L. maackii cover (Table 7). The strongest performing SVI in the linear regression analyses was NDVI with a coefficient of determination $\left(\mathrm{R}^{2}\right)$ equal to 0.6259 (Figure 5; Appendix II, Table AII-1). Numerous transformations of both the dependent and independent variables were performed in an effort to normalize the data and improve the fit of the linear model. None of the transformations improved model fit (Table 8).

A quadratic regression was performed in which L. maackii cover was regressed against NDVI and $\mathrm{NDVI}^{2}$ (Table AII-2). The quadratic model proved a better predictor of L. maackii cover compared to the linear model having a lower root mean square error (RMSE) and a higher $\mathrm{R}^{2}$ value (Table 9; Figure 6).

Stepwise regression was also performed to test the possibility that a combination of reflectance and/or SVIs would improve the detection of L. maackii. Based upon the results of the correlation analysis the available combinations of noncorrelated predictor variables were limited. Predictor variables were selected for inclusion if there was no strong correlation between them, the strength of performance in the linear regression, and their spectral properties. For example, in the model L. maackii cover $=-110+444(\mathrm{NDVI})+21.2(\mathrm{VARI})-694(\mathrm{RB} 1)$ none 
of the predictors were strongly correlated, NDVI performed best in the linear regression, and NDVI's predictive power lies within the red and near infra-red bands, VARI in the green, red, and blue bands, and RB1 band is the blue reflectance band. Predictors were allowed to enter the model if they were significant at the 0.25 level and were retained in the model with a p-value $<0.15$. Three multiple regression models achieved a minimal improvement in $\mathrm{R}^{2}$ values over the single predictor NDVI model, but all were inferior to the quadratic NDVI model (Table 10).

\section{Image Differencing}

The results of the regression analyses of the November 12, 2005 minus January 28, 2002 (Nov-Jan) image values were similar to the results attained from using the November image alone. Of the regression models based upon Nov-Jan SVI and reflectance band training data, NDVI proved to be the best predictor of $L$. maackii cover (Table 11). The linear regression of $L$. maackii percent cover on Nov-Jan NDVI proved to be a slightly better predictor $\left(\mathrm{R}^{2}=0.65\right)$ than using the NDVI values derived from November 12, 2005 image alone $\left(\mathrm{R}^{2}=0.63\right)$. However, the quadratic polynomial regression of $L$. maackii cover on NDVI of the Nov-Jan values $\left(\mathrm{R}^{2}=\right.$ 0.747) was no stronger than the quadratic regression model using the single date November image values $\left(\mathrm{R}^{2}=0.750\right)$.

The June 11, 2007 minus November 12, 2005 image values returned slightly different results. In both the linear and quadratic polynomial regressions, SR performed marginally better than the NDVI. The other SVIs performed as poorly in predicting L. maackii presence as in previous regression analyses. The linear regression of $L$. maackii cover on $\mathrm{SR}\left(\mathrm{R}^{2}=0.52\right)$ and the quadratic polynomial regression of $L$. maackii cover on $\mathrm{SR}\left(\mathrm{R}^{2}=0.63\right)$ (Table 12) both had less predictive power than the quadratic regression model of L. maackii on NDVI using November data.

\section{Model Verification}

The validity of the linear and quadratic models (L. maackii cover to NDVI) was tested with the 15 verification plots. The quadratic polynomial model was an adequate predictor of $L$. maackii cover, with $\mathrm{R}^{2}=0.56$ (Figure 7; Table 12) and was superior to that of the linear model $\mathrm{R}^{2}=0.43$; Figure 8). 


\section{Influence of Other Variables on Model Performance}

The scatterplots from the linear (Figure 5) and quadratic (Figure 6) regression of $L$. maackii on NDVI revealed a high amount of scatter around the regression line at low L. maackii cover abundances. The high NDVI values of some of these points were not expected based upon the low L. maackii cover. I explored whether the unexpected distribution of these points could be due to inter-plot variation in graminoid cover abundance, anthropogenic disturbance, or abundance of Quercus species and Fagus grandifolia in the canopy.

Plots were classified as having high, medium, or low graminoid cover and plotted for the linear (Figure 5) and the quadratic (Figure 6) models. There were 19 woodlots with medium to high graminoid cover and 16 woodlots with low graminoid cover. Twelve of the medium to high graminoid cover plots were to the right of the linear regression line and 11 of these were to the right of the line in the quadratic regression.

The distribution of woodlots with evident anthropogenic disturbance was plotted for the linear (Figure 9) and quadratic (Figure 10) regression of L. maackii on NDVI. There were 12 woodlots with evidence of recent disturbance. In the linear regression 10 of these plots were to the right of the line and in the quadratic regression eight plots were to the right of the line.

Quercus species and Fagus grandifolia do not immediately abscise senesced leaves and retain senesced leaves longer in the fall than other main canopy species (e.g. genera Acer, Fraxinus, and Juglans). The distribution of plots with a combined relative basal area of all Quercus species and Fagus grandifolia equal to or greater than 20\% in the scatterplots from the linear regression (Figure 11) and the quadratic regression (Figure 12) suggests that Quercus and Fagus abundance did not significantly influence NDVI values.

\section{Discussion}

The differences I found in leaf abscission between L. maackii and native tree species confirm that the opportunity exists to use late fall remote sensing data to detect L. maackii in the understory of deciduous forest. Late fall Landsat images predicted L. maackii cover with relative accuracy, because NDVI was not influenced by tree biomass at this time, when the majority of overstory leaves had abscised.

The observed inter-annual variability in leaf fall could complicate efforts to use satellite imagery to detect L. maackii in the understory for years in which the date of overstory canopy 
leaf fall is not known. The observed inter-annual variation in autumn leaf senescence may be due to differences in weather between 2006 and 2007. However, there is no conclusive evidence that temperature plays a major role in governing autumn leaf senescence, but some research indicates that autumn chilling may influence the onset of leaf senescence (Richardson et al. 2006). Observations conducted by Lee et al. (2003) in a mixed northern hardwood forest in Massachusetts over an eight year period found high consistency in the timing of leaf abscission, with only a 6 to 9 day difference between years. Therefore, it may be possible to reliably predict the optimal temporal window for L. maackii detection based upon past observations of leaf abscission, weather data, and/or remote sensing data.

The regression analyses of the SVIs and reflectance bands revealed that NDVI was the best predictor of L. maackii cover. The quadratic polynomial model proved superior to the linear model in predicting L. maackii cover. However, the wide variation in NDVI values for plots with low L. maackii cover indicated that other variables in the woodlots influenced NDVI values. NDVI is sensitive to the reflectance properties of background material. For example, in agricultural settings NDVI is highly influenced by soil reflectance (Baret and Guyot 1991). The poor performance of the EVI and SAVI as predictor variables suggested that background soil reflectance did not influence NDVI values. However, in forested woodlots dominated by deciduous trees one would expect there to be more non-photosynthetically active biomass (i.e. plant litter) than bare soil. NDVI values are influenced by senescent leaves (DiBella et al. 2004) and leaf litter (Van Leeuwen and Huete 1996) and the influence of background material is greater the lower the green biomass cover (Nemani et al. 1993). The wide scatter of NDVI values at low L. maackii cover observed (Figures 5 and 6) may have been a result of the influence of plant litter.

Another possible explanation for the wide scatter of NDVI values at low L. maackii cover is variation in green vegetation cover other than L. maackii. The presence of green biomass in forest understories has been demonstrated to influence reflectance values and interfere in deriving information on forest canopy attributes from remote sensing data using NDVI (e.g. Chen and Cihlar 1996; Turner et al. 1999). The high NDVI values of plots with little L. maackii, but medium to high graminoid cover suggests that graminoids and perhaps other green vegetation reduces the ability of NDVI to predict L. maackii cover, especially at low L. maackii cover values (Figures 5 and 6). 
The distribution of points that exhibited evidence of anthropogenic disturbance (Figures 9 and 10) was similar to the pattern of points with medium to high graminoid cover (Figures 5 and 6) with the majority of disturbed plots to the right of the linear and quadratic regression lines. However, all of the plots with evidence of recent disturbance were also plots with medium or high graminoid abundance and this may indicate that disturbance promotes the presence of graminoids. Disturbance may also facilitate the establishment of other invasive plants (e.g. Rosa multiflora, Berberis thunbergii), as these were more frequently encountered in woodlots with evident anthropogenic disturbance. Furthermore, disturbance activity was primarily timber harvesting and to a lesser extent livestock grazing, both of these could result in changes that would facilitate the establishment of understory vegetation. Therefore, disturbance may influence NDVI values by promoting the presence of green vegetation other than $L$. maackii. Timber harvesting could also influence NDVI values by reducing canopy cover, stand structure, and reducing shadow effects, which would result in increased NDVI values (MacDonald et al. 1998).

The availability of Landsat $5 \mathrm{TM}$ data for this study was limited to one suitable image that was free of cloud cover over the study area from the period 2001 to 2007. Fall Landsat 7 ETM+ was not considered due to the scan line corrector failure that occurred in May 2003. Different remote sensing platforms could offer additional opportunities for the acquisition of cloud free images. For example, the SPOT platform could acquire an image of the study area for any day specified.

The accuracy of the quadratic NDVI model could be improved by increasing the spectral resolution of the remote sensing data and the amount of field data collected. Combining higher spectral resolution remote sensing data with field measurements of L. maackii green leaf reflectance could increase the level of discrimination between L. maackii and other green vegetation. If the spectral reflectance characteristics of L. maackii, as well as other vegetation present in the study area were collected, then these values could be used to develop a predictive model with improved discrimination between $L$. maackii and other vegetation cover types (Lass et al. 2005). The collection of quantitative data pertaining to the spectral reflectance properties of all above ground biomass (green leaf, litter, bark) would provide information about other factors influencing the reflectance values of study plots and enable one to reduce the influence of background reflectance on the predictive model (Van Leeuwen and Huete 1996). 
Improvements in the detection of L. maackii cover may be achieved through the use of multiple remote sensing platforms, as this technique has been used to achieve improved model performance for the estimation of above ground biomass ( $\mathrm{Lu}$ 2006). By combining information from a broadband platform with information from a hyperspectral platform the degree of discrimination between vegetation cover types would be expected to increase and an improvement in predictive power achieved.

Improvements in the predictive model may also be realized by the collection of more field data. There were 35 training plots and only eight of those had L. maackii cover greater than $20 \%$. A greater number of high cover plots could reduce the influence of outliers and improve model fit for the training data. The weakness of fit in the verification model may be due to the small data set. There were only 15 verification plots and only two of those had greater than $20 \%$ L. maackii cover.

It is plausible that the spatio-temporal distribution of L. maackii could be mapped using remote sensing data. The Landsat 1 platform began collecting data in 1972 and SPOT 1 was launched in 1986. Mapping the distribution of L. maackii populations across the landscape over a 20 to 36 year period would provide insight into mechanisms that facilitate L. maackii invasion.

The results of this study demonstrate that NDVI may be used to predict the cover of the exotic shrub L. maackii in the understory of deciduous woodlots in the study area. Such a predictive model could be used to map the temporal and spatial distribution of L. maackii within the Eastern Broadleaf Ecoregion, as models developed in one study area may be used in other areas with similar biophysical environments if atmospheric correction methods are properly applied ( $\mathrm{Lu}$ 2006). This model could also be used to predict the presence of other exotic invasive species that have similar leaf phenology characteristics (e.g. Lonerica tatarica, Ligustrum sinense, Berberis thunbergii) in the understories of eastern deciduous forests. 


\section{Works Cited}

Andersen, M. C., H. Adams, B. Hope, and M. Powell. 2004. Risk analysis for invasive species: general framework and research needs. Risk Analysis 24(4):893-900.

Anderson, G. L., E. S. Delfosse, N. R. Spencer, C. W. Prosser, and R. D. Richard. 2003. Lessons in developing successful invasive weed control programs. Journal of Range Management $56: 2-12$.

Baret, F. and G. Guyot. 1991. Potential and limits of vegetation indexes for LAI and APAR assessment. Remote Sensing of Environment 35(2-3):161-173.

Bartuszevige, A. M., and D. L. Gorchov. 2006. Avian seed dispersal of an invasive shrub. Biological Invasions, 8: 1013-1022.

Bartuszevige, A. M., D. L. Gorchov, and L. Raab. 2006. The relative importance of landscape and community features in the invasion of an exotic shrub in a fragmented landscape. Ecography 29(2):213-222.

Birth, G. S. and G. R. McVey. 1968. Measuring the color of growing turf with a reflectance spectrophotometer. Agronomy Journal 60:640-643.

Byers, J. E., S. Reichard, J. M. Randall, I. M. Parker, C. S. Smith, W. M. Lonsdale, I. A. E. Atkinson, T. R. Seastedt, M. Williamson, E. Chornesky, and D. Hayes. 2001. Directing research to reduce the impacts of exotic species. Conservation Biology 16(3): 630-640.

Chavez, P. S. Jr. 1996. Image-based atmospheric corrections: revisited and improved. Photgrammetric Engineering and Remote Sensing. 62:1025-1036.

Chander, G., B. L. Markham, and J. A. Barsi. 2007. Revised Landsat-5 Thematic Mapper radiometric calibration. Geoscience and Remote Sensing Letters, IEEE 4(3): 490-494.

Chen, J. M. and J. Cihlar. 1999. Retrieving leaf area index of boreal conifer forests using Landsat TM images. Remote Sensing of Environment 55:153-162.

Chornesky, E. A., A. M. Bartuska, G. H. Aplet, K. O. Britton, J. Cummings-Carlson, F. W. Davis, J. Eskow, D. R. Gordon, K. W. Gottschalk, R. A. Haack, A. J. Hansen, R. N. Mack, F. J. Rahel, M. A. Shannon, L. A. Wainger, and T. B. Wigley. 2005. Science priorities for reducing the threat of invasive species to sustainable forestry. Bioscience 55:335-348.

Cipollini, D., R. Stevenson, S. Enright, A. Eyles, and P. Bonello. 2008. Phenolic metabolites in leaves of the invasive shrub, Lonicera maackii, and their potential phytotoxic and antiherbivore effects. Journal of Chemical Ecology 34:144-152. 
Cohen, W. B. and S. N. Goward. 2004. Landsat's role in ecological applications of remote sensing. Bioscience 54:535-545.

Cohen, W. B. 1991. Response of vegetation indices to changes in three measures of leaf water stress. Photogrammetric Engineering and Remote Sensing 57(2):195-202.

Collier, M. H., Vankat, J. L., and M. R. Hughes. 2002. Dimished plant richness and abundance below Lonicera maackii, an invasive shrub. American Midland Naturalist 147:60-71.

Cooksey, D. and R. Sheley. 1997. Noxious weed survey and mapping system. Rangelands 19:2023.

Crist, E. P. and R. J. Cicone. 1984. Application of the Tasseled Cap concept to simulated Thematic Mapper data. Photogrammetric Engineering and Remote Sensing 50(3):343352.

Crist, E. P. and R. J. Kauth. 1986. The Tasseled Cap de-mystified. Photogrammetric Engineering and Remote Sensing 52(1):81-86.

Deckers, B., K. Verheyen, M. Hermy, and B. Muys. 2005. Effects of landscape structure on the spread of black cherry Prunus serotina in an agricultural landscape in Flanders, Belgium. Ecography, 28: 99-109.

Di Bella, C. M., J. M. Paruelos, J. E. Becerra, C. Bacour, and F. Baret. 2004. Effect of senescent leaves on NDVI-based estimates of $f$ APAR: experimental and modeling evidences. International Journal of Remote Sensing 25(23):5415-5427.

Dorning, M. and D. Cipollini. 2006. Leaf and root extracts of the invasive shrub, Lonicera maackii, inhibit seed germination of three herbs with no autotoxic effects. Plant Ecology 184:287-296.

Fisher, J. I., J. F. Mustard, and M. A. Vadeboncoeur. 2006. Green leaf phenology at Landsat resolution: scaling from the field to the satellite. Remote Sensing of the Environment 100(2): 265-279.

Gitelson, A. A., Y. J. Kaufman, R. Stark, and D. Rundquist. 2002. Novel algorithms for remote estimation of vegetation fraction. Remote Sensing of Environment 80:76-87.

Gorchov, D. L. and D. E. Trisel. 2003. Competitive effects of the invasive shrub Lonicera maackii(Rpr.) Heider (Caprifoliaceae) on growth and survival of native tree seedlings. Plant Ecology 166:13-24.

Gould, A. M. A. and D. L. Gorchov. 2000. Effects of the exotic invasive shrub Lonicera maackii on the survival and fecundity of three species of native annuals. American Midland Naturalist 144:36-50. 
Hamada, Y., D. A. Stow, L. L. Coulter, J. C. Jafolla, and L. W. Hendricks. 2007. Detecting Tamarisk species (Tamarix spp.) in riparian habitats of Southern California using high spatial resolution hyperspectral imagery. Remote Sensing of Environment 109:237-248.

Hardisky, M. A., V. Klemas, and R. M. Smart. 1983. The influence of soil salinity, growth form, and leaf moisture on the spectral radiance of Spartina alterniflora canopies.

Photogrammetric Engineering and Remote Sensing 49:47-83.

Hartman, K. M. and B. C. McCarthy. 2004. Restoration of a forest understory after the removal of an invasive shrub, Amur Honeysuckle (Lonicera maackii). Restoration ecology 12:154-165.

Hartman, K. M. and B. C. McCarthy. 2007. A dendro-ecological study of forest overstory productivity following the invasion of the non-indigenous shrub Lonicera maackii. Applied Vegetation Science 10:3-14.

Hooper, D. U., F. S. Chapin III, J. J. Ewel, A. Hector, P. Inchautsi, S. Lavorel, J. H. Lawton, D. M. Lodge, M. Loreau, S. Naeem, B. Schmid, H. Setala, A. J. Symstad, J. Vandermeer, and D. A. Wardle. 2005. Effects of biodiversity on ecosystem functioning: a consensus of current knowledge. Ecological Monographs 75(1):3-35.

Huang, C., Wylie, B., Yang, L., Homer, C., and G. Zylstra. 2002. Derivation of a Tasseled Cap Transformation based on Landsat 7 at-satellite reflectance. International Journal of Remote Sensing 23(8):1741-1748.

Huete, A. R. 1988. A soil-adjusted vegetation index (SAVI). Remote Sensing of the Environment 25:295-309.

Hutchinson, T. F. and J. L. Vankat. 1997. Invasibility and effects of Amur Honeysuckle in southwestern Ohio forests. Conservation Biology 11:1117-1124.

Jensen, J. R. 2007. Remote Sensing of the Environment: an Earth Resource Perspective. Upper Saddle River, NJ. Pearson Education, Inc.

Joshi C., J. DeLeeuw, J. Van Andel, A. K. Skidmore, H. D. Lekhak, I. C. Van Duren, and N. Norbu. 2006. Indirect remote sensing of a cryptic forest understory invasive species. Forest Ecology and Management, 225: 245-256.

Kauth, R. J. and G. S. Thomas. 1976. The Tasseled Cap - a graphic description of the spectraltemporal development of agricultural crops as seen by Landsat. Proceedings of the LACIE Symposium, Houston:NASA 705-721.

Kerr, J. T. and M. Ostrovsky. 2003. From space to species: ecological applications for remote sensing. Trends in Ecology and Evolution 18(6):299-305. 
Laba, M., R. Downs, S. Smith, S. Welsh, C. Neider, S. White, M. Richmond, W. Philpot, and P. Baveye. 2008. Mapping invasive wetland plants in the Hudson River National Estuarine Research Reserve using quickbird satellite imagery. Remote Sensing of Environment 112:286-300.

Lass, L. W., T. S. Prather, N. F. Glenn, K. T. Weber, J. T. Mundt, and J. Pettinghill. 2005. A review of remote sensing of invasive weeds and example of the early detection of spotted knapweed (Centuarea maculosa) and babybreath (Gypsophila paniculata) with hyperspectral sensor. Weed Science 53:242-251.

Lawrence, R. L., S. D. Wood, and R. L. Sheley. 2006. Mapping invasive plants using hyperspectral imagery and Breiman Cutler classifications (RandomForest). Remote Sensing of Environment 100:356-362.

Lee, D. W., J. O'Keefe, N. M. Holbrook, and T. S. Field. 2003. Pigment dynamics and autumn leaf senescence in a New England deciduous forest, eastern USA. Ecological Research 18:677-694.

Leica Geosystems. 2003. ERDAS field guide: $7^{\text {th }}$ edition. GIS and Mapping, LLC. Atlanta, Georgia.

Leung, B., D. Finnhoff, J. F. Shogren, and D. Lodge. 2005. Managing invasive species: rules of thumb for rapid assessment. Ecological Economics 55:(24-36).

Lu, D. 2006. The potential and challenge of remote sensing-based biomass estimation. International Journal of Remote Sensing 27(7):1297-1328.

Luken, J. O. and J. W. Thieret. 1995. Amur honeysuckle (Lonicera maackii, Caprifoliaceae): its ascent, decline, and fall. Sida 16:479-503.

MacDonald, A. J., F. M. Gemmel, and P. E. Lewis. 1998. Investigation of the utility of spectral vegetation indices for determining information on coniferous forests. Remote Sensing of Environment 66(3):250-272.

Markham, B.L., and J.L. Barker. 1986. Landsat MSS and TM post-calibration dynamic ranges, exoatmospheric reflectances and at-satellite temperatures. EOSAT Technical Notes, August 1986.

Mauz, K. 2002. New improved procedure for minimum DN selection for input to the COST model for atmospheric correction. Arizona Remote Sensing Center, Office of Arid Lands Studies. Available at http://arsc.arid.arizona.edu/resources/image processing/landsat/minimum-dn.html; accessed March 20, 2008.

Miller, K. and D. L. Gorchov. 2004. The invasive shrub Lonicera maackii, reduced growth and fecundity of perennial forest herbs. Oecologia 139:359-375. 
Moshier, S. 2000. Astronomy and numerical software source codes. Available at http://www.moshier.net/\#Astronomy; accessed October 16, 2007.

Nemani, R., L. Pierce, S. Running, and L. Band. 1993. Forest ecosystem processes at the watershed scale: sensitivity to remotely-sensed leaf area index estimates. Journal of Remote Sensing 14:2519-2534.

Noonan, M. and C. Chafer. 2006. A method for mapping the distribution of willow at a catchment scale using bi-seasonal SPOT5 imagery. Weed Research 47:173-181.

Nordberg, M. L. and J. Evertson. 2003. Monitoring change in mountainous dry-heath vegetation at a regional scale using multitemporal Landsat TM data. AMBIO: A Journal of the Human Environment 32(8): 502-509.

Parker, I. M., D. Simberloff, W. M. Lonsdale, K. Goodell, M. Wonham, P. M. Kareiva, M. H. Williamson, B. Von Holle, P. B. Moyle, J. E. Byers, and L. Goldwasser. 1999. Impact: toward a framework for understanding the ecological effects of invaders. Biological Invasions 1: 3-19.

Patil, G. P., R. P. Brooks, W. L. Myers, D. J. Rapport, and C. Taillie. 2001. Ecosystem health and its measurement at landscape scale: towards the next generation of quantitative assessments. Ecosystem Health 7(4):307-315.

Pengra, B. W., C. A. Johnston, and T. R. Loveland. 2007. Mapping an invasive plant, Phragmites australis, in coastal wetlands using the EO-1 Hyperion hyperspectral sensor. Remote Sensing of Environment 108:74-81.

Peterson, E. B. 2005. Estimating cover of an invasive grass (Bromus tectorum) using tobit regression and phenology derived from two dates of Landsat ETM+ data. International Journal of Remote Sensing 26(12):2491-2507.

Pimentel, D., L. Lach, R. Zuniga, and D. Morrison. 2000. Environmental and economic costs of exotic species in the United States. BioScience 50(1): 53-65.

Resasco, J., A. N. Hale, M. C. Henry, and D. L. Gorchov. 2007. Detecting an invasive shrub in a deciduous forest understory using late-fall LANDSAT sensor imagery. International Journal of Remote Sensing 28(16):3739-3745.

Rew, L. J., B. D. Maxwell, and R. Aspinall. 2005. Predicting the occurrence of nonindigenous species using environmental and remotely sensed data. Weed Science 53:236-241.

Richardson, A. D., A. S. Bailey, E. G. Denny, C. W. Martin, and J. O’Keefe. 2006. Phenology of a northern hardwood forest canopy. Global Climate Change Biology 12:1174-1188. 
Rouse, J. W. Jr., R. H. Haas, J. A. Schell, and D. W. Deering. 1974. Monitoring vegetation systems in the Great Plains with ERTS. Proceedings of the Third Earth Resources Technology Satellite-1 Symposium, Greenbelt:NASA SP-351:3010-3017.

Schmidt, K. A. and C. J. Whelan. 1999. Effects of exotic Lonicera and Rhamnus on songbird nest predation. Conservation Biology 13(6):1502-1506.

Shaw, D. R. 2005. Symposium: Translation of remote sensing data into weed management decisions. Weed Science 53:264-273.

Smith, R. L. and T. M. Smith. 2001. Ecology and Field Biology. $6^{\text {th }}$ edition. Benjamin Cummins, San Fransciso.

Stumpfk, K. A. 1993. The estimation of forest vegetation cover descriptions using a vertical densitometer. Geographic Resource Solutions. Arcata, CA. Available at http://www.grsgis.com/publications/saf 93.pdf; accessed October 3, 2005.

Trisel, D. E. 1997. The invasive shrub Lonicer maackii (Rupr.) Herder (Caprifoliaceae): factors contributing to its success and its effect on native species. PhD Dissertation, Miami University, Oxford, USA.

Trisel, D. E. and D. L. Gorchov. 1994. Regional distribution, leaf phenology, and herbivory of the invasive shrub, Lonicera maackii. Bulletin of the Ecological Society of America 75:231-232.

Turner, D. P., W. B. Cohen, R. E. Kennedy, K. S. Fassnacht, and J. M. Briggs. 1999. Relationships between leaf area index and Landsat TM spectral vegetation indices across three temperate zone sites. Remote Sensing of the Environment 70:52-68.

USGS, 2001. MLRC Image Preprocessing Procedure, US Department of Interior.

Van Leeuwen, W. J. D. and A. R. Huete. 1996. Effects of standing litter on the biophysical interpretation of plant canopies with spectral indices. Remote Sensing of Environment $55: 123-138$.

Vitousek, P. M. 1990. Biological invasions and ecosystem processes: toward an integration of population biology and ecosystem studies. Oikos 57(1):7-13.

Wilcove, D. S., D. Rothstein, J. Dubow, A. Phillips, and E. Loso. 1998. Quantifying threats to imperiled species in the United States. Bioscience 48:607-615.

Wilson, E. H. and S. A. Sader. 2002. Detection of forest harvest type using multiple dates of Landsat TM imagery. Remote Sensing of Environment 80:385-396. 
Table 1 Lonicera maackii cover classes and number of ground plots (GPs) within each level of L. maackii cover.

\begin{tabular}{|cccc|}
\hline $\begin{array}{c}\text { Percent } \text { L. maackii } \\
\text { cover }\end{array}$ & $\begin{array}{c}\text { Total GPs within } \\
\text { each cover class }\end{array}$ & Training GPs & Verification GPs \\
\hline $\mathbf{4 0 - 8 0}$ & 4 & 3 & 1 \\
\hline $\mathbf{3 0 - 3 9 . 9}$ & 3 & 2 & 1 \\
\hline $\mathbf{1 9 - 2 9 . 9}$ & 4 & 3 & 1 \\
\hline $\mathbf{1 0 - 1 8 . 9}$ & 7 & 5 & 2 \\
\hline $\mathbf{6 - 9 . 9}$ & 12 & 8 & 4 \\
\hline $\mathbf{2 - 5 . 9}$ & 5 & 4 & 2 \\
\hline $\mathbf{. 1 - 1 . 9}$ & 7 & 5 & 3 \\
\hline $\mathbf{0}$ & 8 & 5 & 15 \\
\hline TOTALS & 50 & 35 & 1 \\
\hline
\end{tabular}

Table 2 Spectral and spatial characteristics of Landsat 5 TM and Landsat7 ETM+ where IR=infra red (modified from Jensen 2007).

\begin{tabular}{|ccc|}
\hline Band & Spectral Resolution $(\boldsymbol{\mu m})$ & Spatial Resolution $(\mathbf{m})$ \\
\hline $\mathbf{1}$ (blue) & $0.45-0.52$ & $30 \times 30$ \\
\hline $\mathbf{2}$ (green) & $0.52-0.60$ & $30 \times 30$ \\
\hline $\mathbf{3}$ (red) & $0.63-0.69$ & $30 \times 30$ \\
\hline $\mathbf{4}$ (near IR) & $0.76-0.90$ & $30 \times 30$ \\
\hline $\mathbf{5}$ (mid IR) & $10.4-12.5$ & $30 \times 30$ \\
\hline $\mathbf{7}$ (mid IR) & $2.08-2.35$ & $30 \times 30$ \\
\hline
\end{tabular}

Table 3 Conversion equations for Landsat5 image digital number values to Landsat7 equivalents (USGS 2001).

\begin{tabular}{|cc|}
\hline Band/Layer & Values for Landsat $\mathbf{5}$ conversion to Landsat $\mathbf{7}$ \\
\hline $\mathbf{1 / 1}$ & (layer1) $^{*} 0.9398+4.2934$ \\
\hline $\mathbf{2} / \mathbf{2}$ & (layer2) $* 1.7731+4.7289^{*}$ (layer3) $^{*} 1.5348+3.9796$ \\
\hline $\mathbf{3 / 3}$ & (layer4) $^{*} 1.4239+7.032$ \\
\hline $\mathbf{4 / 4}$ & (layer5) $^{*} 0.9828+7.0185$ \\
\hline $\mathbf{5 / 5}$ & (layer6) $^{*} 1.3017+7.6568$ \\
\hline $\mathbf{7 / 6}$ &
\end{tabular}


Table 4 Image and band specific equation values for digital numbers (DN) to radiance conversion.

\begin{tabular}{|ccc|}
$\begin{array}{c}\text { Band/ } \\
\text { Layer }\end{array}$ & $\begin{array}{c}\text { DN to Radiance Equation Values } \\
\text { for June 11, 2007 }\end{array}$ & $\begin{array}{c}\text { DN to Radiance Equation Values } \\
\text { for November 12, 2005 and } \\
\text { January 28, 2002 }\end{array}$ \\
\hline $\mathbf{1 / 1}$ & $-6.2+((191.6+6.2) / 255) *($ layer 1$)$ & $-6.2+((191.6+6.2) / 255) *($ layer 1$)$ \\
\hline $\mathbf{2} / \mathbf{2}$ & $-6.4+((196.5+6.4) / 255) *($ layer 2$)$ & $-6.4+((196.5+6.4) / 255) *($ layer 2$)$ \\
\hline $\mathbf{3 / 3}$ & $-5+((152.9+5) / 255) *($ layer 3$)$ & $-5+((152.9+5) / 255) *($ layer 3$)$ \\
\hline $\mathbf{4 / 4}$ & $-5.1+((241.1+5.1) / 255) *($ layer 4$)$ & $-5.1+((157.4+5.1) / 255) *($ layer 4$)$ \\
\hline $\mathbf{5 / 5}$ & $-1+((31.06+1) / 255) *($ layer 5$)$ & $-1+((31.06+1) / 255) *($ layer 5$)$ \\
\hline $\mathbf{7 / 6}$ & $-0.35+((10.8+0.35) / 255) *($ layer 6$)$ & $-0.35+((10.8+0.35) / 255) *($ layer 6$)$ \\
\hline
\end{tabular}

Table 5 Individual COST model equations for each band and image date.

\begin{tabular}{|c|c|}
\hline $\begin{array}{l}\text { Band/ } \\
\text { Layer }\end{array}$ & COST Equation Values for June 11, 2007 \\
\hline B1/L1 & $(3.14159 *($ layer 1$)-35.5312) * 1.030852365481) /(1969 * 0.822849376$ \\
\hline B2/L2 & $(3.14159 *($ layer 2$)-25.9196) * 1.030852365481) /(1840 * 0.822849376737328)$ \\
\hline B3/L3 & $(3.14159 *($ layer 3$)-8.6681) * 1.030852365481) /(1551 * 0.822849376737328)$ \\
\hline B4/L4 & $(3.14159 *($ layer 4$)-8.5891) * 1.030852365481) /(1044 * 0.822849376737328)$ \\
\hline B5/L5 & $(3.14159 *($ layer 5$)-0.0462) * 1.030852365481) /(225.7 * 0.822849376737328)$ \\
\hline B7/L6 & $(3.14159 *($ layer 6$)-0) * 1.030852365481) /(82.07 * 0.822849376737328)$ \\
\hline $\begin{array}{l}\text { Band/ } \\
\text { Layer }\end{array}$ & COST Equation Values for November 12, 2005 \\
\hline B1/L1 & $(3.14159 *($ layer 1$)-18.7470) * 0.97971948) /(1969 * 0.238347103014051)$ \\
\hline B2/L2 & $(3.14159 *($ layer 2$)-10.8962) * 0.97971948) /(1840 * 0.822849376737328)$ \\
\hline B3/L3 & $(3.14159 *($ layer 3$)-1.5348) * 0.97971948) /(1551 * 0.238347103014051)$ \\
\hline B4/L4 & $(3.14159 *($ layer 4$)-1.2270) * 0.97971948) /(1044 * 0.238347103014051)$ \\
\hline B5/L5 & $(3.14159 *($ layer 5$)-0) * 0.97971948) /(225.7 * 0.238347103014051)$ \\
\hline B7/L6 & $(3.14159 *($ layer 6$)-0) * 0.97971948) /(82.07 * 0.238347103014051)$ \\
\hline $\begin{array}{l}\text { Band/ } \\
\text { Layer }\end{array}$ & COST Equation Values for January 28, 2002 \\
\hline B1/L1 & $(3.14159 *($ layer 1$)-28.2620) * 0.969809965) /(1969 * 0.202426144)$ \\
\hline B2/L2 & $(3.14159 *($ layer 2$)-36.4992) * 0.969809965) /(1840 * 0.202426144)$ \\
\hline B3/L3 & $(3.14159 *($ layer 3$)-15.7755) * 0.969809965) /(1551 * 0.202426144)$ \\
\hline B4/L4 & $(3.14159 *($ layer 4$)-9.8441) * 0.969809965) /(1044 * 0.202426144)$ \\
\hline B5/L5 & $(3.14159 *($ layer 5$)-0.6923) * 0.969809965) /(225.7 * 0.202426144)$ \\
\hline B7/L6 & $(3.14159 *($ layer 6$)-0.3181) * 0.969809965) /(82.07 * 0.202426144)$ \\
\hline
\end{tabular}


Table 6 Pearson's correlation coefficients for the four SVIs most strongly correlated with amount of $L$. maackii cover for the November 12, 2005 training data $(\mathrm{N}=35)$.

\begin{tabular}{|ccc|}
\hline SVI & Pearson's Correlation Coefficient & p-value \\
\hline NDVI & 0.791 & $<.0001$ \\
\hline SR & -0.782 & $<.0001$ \\
\hline EVI & 0.609 & $<.0001$ \\
\hline NDMI & 0.604 & $<.0001$ \\
\hline
\end{tabular}

Table $7 R^{2}$ and $p$ values from the least squares regression analysis of the November 12, 2005 training data $(N=35)$ where L. maackii cover was regressed on individual SVI and reflectance band (RB) values.

\begin{tabular}{|c|c|c|c|}
\hline SVI & Linear Regression Model & $\mathbf{R}^{\mathbf{2}}$ & $\begin{array}{l}\text { p-value } \\
(\alpha=.05)\end{array}$ \\
\hline NDVI & L. maackii cover $=-207+484(\mathrm{NDVI})$ & 0.626 & $<0.0001$ \\
\hline SR & L. maackii cover $=207-516(\mathrm{SR})$ & 0.612 & $<0.0001$ \\
\hline EVI & L. maackii cover $=-116-389(\mathrm{EVI})$ & 0.371 & 0.0001 \\
\hline NDMI & L. maackii cover $=40.7+290(\mathrm{NDMI})$ & 0.365 & 0.0001 \\
\hline TCap wetness & L. maackii cover $=128+329($ TCapW $)$ & 0.322 & 0.0004 \\
\hline RB 7 & L. maackii cover $=115-481(\operatorname{COST} 7)$ & 0.311 & 0.0005 \\
\hline SAVI & L. maackii cover $=-118+418(\mathrm{SAVI})$ & 0.305 & 0.0006 \\
\hline RB 3 & L. maackii cover $=109-816($ COST3 $)$ & 0.303 & 0.0006 \\
\hline RB 5 & L. maackii cover $=134-320($ COST5 $)$ & 0.292 & 0.0008 \\
\hline TCap greeness & L. maackii cover $=-29.7+642(\mathrm{TCapG})$ & 0.260 & 0.0017 \\
\hline RB 1 & L. maackii cover $=160-2043(\operatorname{COST} 1)$ & 0.245 & 0.0025 \\
\hline TCap brightness & L. maackii cover $=81.6-163(\mathrm{TCapB})$ & 0.083 & 0.0936 \\
\hline RB 2 & L. maackii cover $=46.2-1380(\mathrm{COST} 2)$ & 0.021 & 0.0025 \\
\hline VARI & L. maackii cover $=6.5-4.9$ (VAR) & 0.001 & 0.9021 \\
\hline RB 4 & L. maackii cover $=13.7-1($ COST4 $)$ & 0.000 & 0.9924 \\
\hline
\end{tabular}

Table $8 R^{2}$ and p-values from linear regression analyses of various data transformations applied to the November 12 , 2005 training data $(\mathrm{N}=35)$, where $L$. maackii was regressed on NDVI.

\begin{tabular}{|ccc|}
\hline Transformation & $\mathbf{R}^{\mathbf{2}}$ & p-value ( $\boldsymbol{\alpha}=\mathbf{. 0 5})$ \\
\hline $\log$ NDVI & 0.619 & 0.0001 \\
\hline NDVI & 0.635 & 0.0001 \\
\hline VNDVI & 0.694 & 0.0001 \\
\hline 1/VNDVI & 0.594 & 0.0580 \\
\hline 1/NDVI & 0.105 & 0.0001 \\
\hline Log $($ L. maackkii $+\mathbf{1})$ & 0.583 & 0.0001 \\
\hline VL. maackii & 0.408 & 0.0001 \\
\hline VNDVI and VL. maackii & 0.532 & 0.0001 \\
\hline
\end{tabular}


Table 9 Comparison of $R M S E, \mathbf{R}^{2}$, and p-values of the linear regression model to the quadratic polynomial regression model for the November 12, 2005 training data $(\mathrm{N}=35)$ where $L$. maackii cover was regressed on NDVI.

\begin{tabular}{|lccc|}
\hline \multicolumn{1}{|c}{ Regression Model } & RMSE & $\mathbf{R}^{\mathbf{2}}$ & $\begin{array}{c}\text { p-value } \\
(\boldsymbol{\alpha}=.05)\end{array}$ \\
\hline L. maackii \%cover=1165 - 5397(NDVI)+6273(NDVI ${ }^{2}$ ) & 8.96 & 0.750 & $<.0001$ \\
\hline L. maackii \%cover= $=\mathbf{- 2 0 7}+\mathbf{4 8 4}(\mathbf{N D V I})$ & 10.80 & 0.626 & $<.0001$ \\
\hline
\end{tabular}

Table 10 Stepwise multiple regression models and analysis values for the November 12, 2005 training data $(N=35)$ where $\mathrm{Y}=$ L. maackii percent cover and the various SVIs and reflectance bands are the dependent variables. Mallows $\mathrm{C}_{(\mathrm{p})}$ statistic is related to the mean square error of a fitted value and identifies parsimonious models with good predictive power. The better model is one where Mallows' $\mathrm{Cp}$ is small and close to the number of predictors in the model plus the constant (p).

\begin{tabular}{|c|c|c|c|}
\hline Regression Model & $\mathbf{R}^{2}$ & $\begin{array}{c}\text { p-value } \\
(\alpha=.05)\end{array}$ & $\begin{array}{c}\text { Mallow's } \\
\mathrm{C}_{(\mathrm{p})}\end{array}$ \\
\hline $\mathrm{Y}=-110+444(\mathrm{NDVI})+21.2($ & 0.656 & 0.0001 & 2.7 \\
\hline $\mathrm{Y}=-167+468(\mathrm{NDVI})-77.7$ (TCapBrightness) & 0.644 & $<0.0001$ & 2.6 \\
\hline $\mathrm{Y}=-185+497(\mathrm{NDVI})-89($ Reflectance4) & 0.643 & 0.0001 & 2.5 \\
\hline$Y=-23.2+425($ SAVI $)-828($ Reflectance 3$)$ & 0.618 & 0.0001 & 3.0 \\
\hline$Y=90.8+331(E V I)-333($ Reflectance 5$)+44.8($ VARI $)$ & 0.617 & $<0.0001$ & 4 \\
\hline $\mathrm{Y}=29.7+384(\mathrm{EVI})-2000($ Reflectance 1$)$ & 0.606 & $<0.0001$ & 3 \\
\hline $\mathrm{Y}=1165.3-5397(\mathrm{NDVI})+6273.3\left(\mathrm{NDVI}^{2}\right)$ & 0.750 & 0.0009 & 3 \\
\hline
\end{tabular}

Table 11 Results of the linear and quadratic polynomial regression analyses of $L$. maackii on the top performing SVI from the January 28, 2002 minus November 12, 2005 training data values $(\mathrm{N}=35)$ and the June 11, 2007 minus

November 12, 2005 training data values

\begin{tabular}{|llccc|}
\hline \multicolumn{1}{|c}{ Regression Model } & Image Dates & RMSE & $\mathbf{R}^{\mathbf{2}}$ & $\begin{array}{c}\text { p-value } \\
(\boldsymbol{\alpha}=.05)\end{array}$ \\
\hline L. maackii $\%$ cover $=$ NDVI NDVI ${ }^{2}$ & Nov-Jan & 9.02 & 0.747 & $<.0001$ \\
\hline L. maackii $\%$ cover $=$ NDVI & Nov-Jan & 10.45 & 0.650 & $<.0001$ \\
\hline L. maackii $\%$ cover $=$ SR SR ${ }^{2}$ & Jun-Nov & 10.94 & 0.628 & $<.0001$ \\
\hline L. maackii $\%$ cover $=$ SR & Jun-Nov & 12.17 & 0.525 & $<.0001$ \\
\hline
\end{tabular}

Table $12 R^{2}$ and p-values from the regression analysis of the November 12, 2005 verification data $(N=15)(Y=$ observed L. maackii cover, $\mathrm{X}=$ predicted $L$. maackii cover).

\begin{tabular}{|cccccc|}
\hline SVI & $\begin{array}{c}\text { Training Data } \\
\text { Regression Model }\end{array}$ & $\begin{array}{c}\text { Verification Data } \\
\text { Model }\end{array}$ & RMSE & $\mathbf{R}^{\mathbf{2}}$ & $\begin{array}{c}\text { p-value } \\
(\boldsymbol{\alpha}=.05)\end{array}$ \\
\hline NDVI & OLS & $\mathrm{Y}=-1.20+1.02(\mathrm{x})$ & 14.91 & 0.426 & 0.008 \\
\hline NDVI & Quadratic & $\mathrm{Y}=-2.99+1.317(\mathrm{x})$ & 13.11 & 0.556 & 0.001 \\
\hline
\end{tabular}


Figure 1 Distribution of plots represented with black circles within the study area. The inset window displays the location and extent of Landsat Path 20 Row 32 coverage and the location of the study area within that extent.

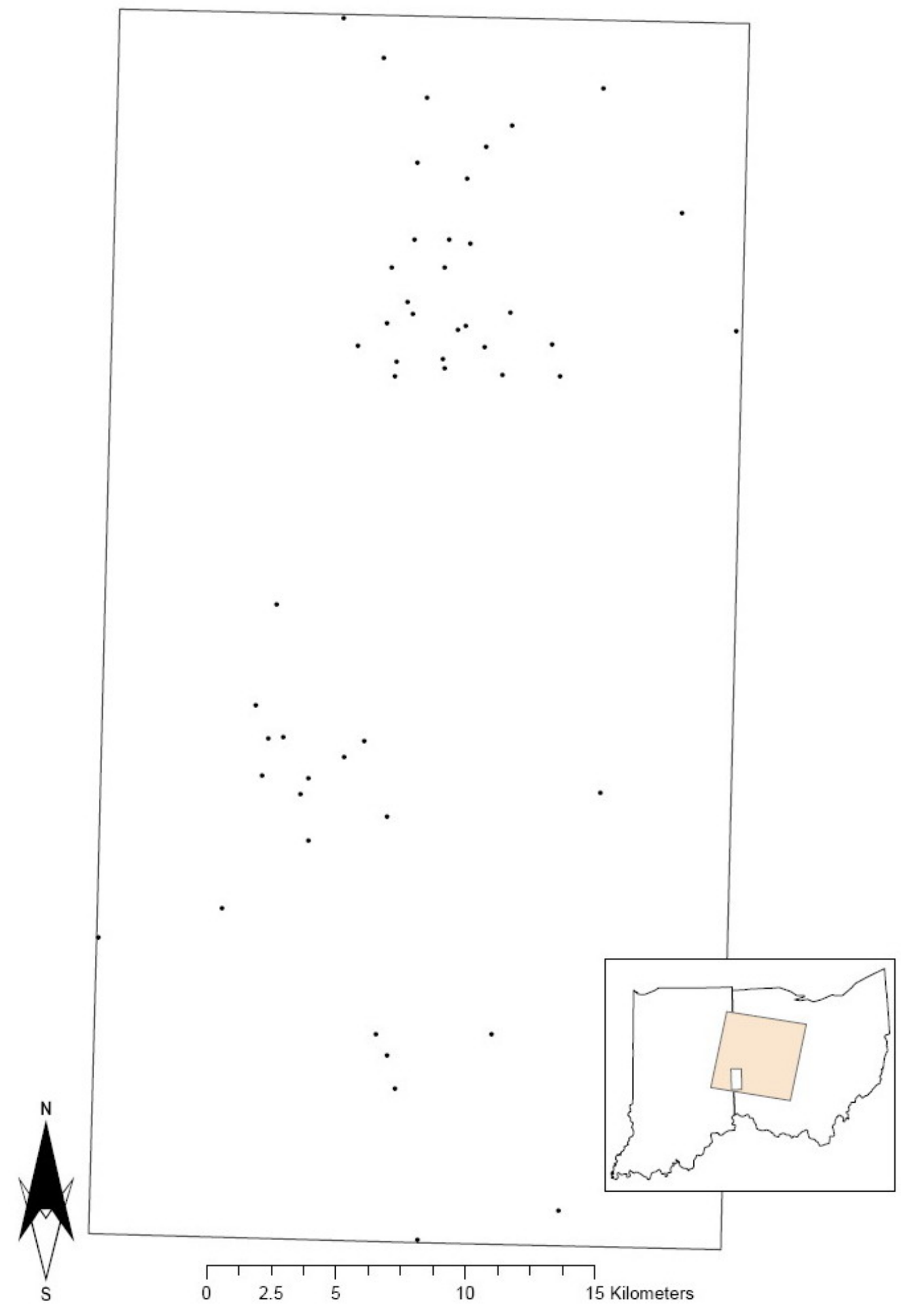


Figure 2 Polygons drawn in ArcMap over suitable woodlots using mosaiced DOQQs.

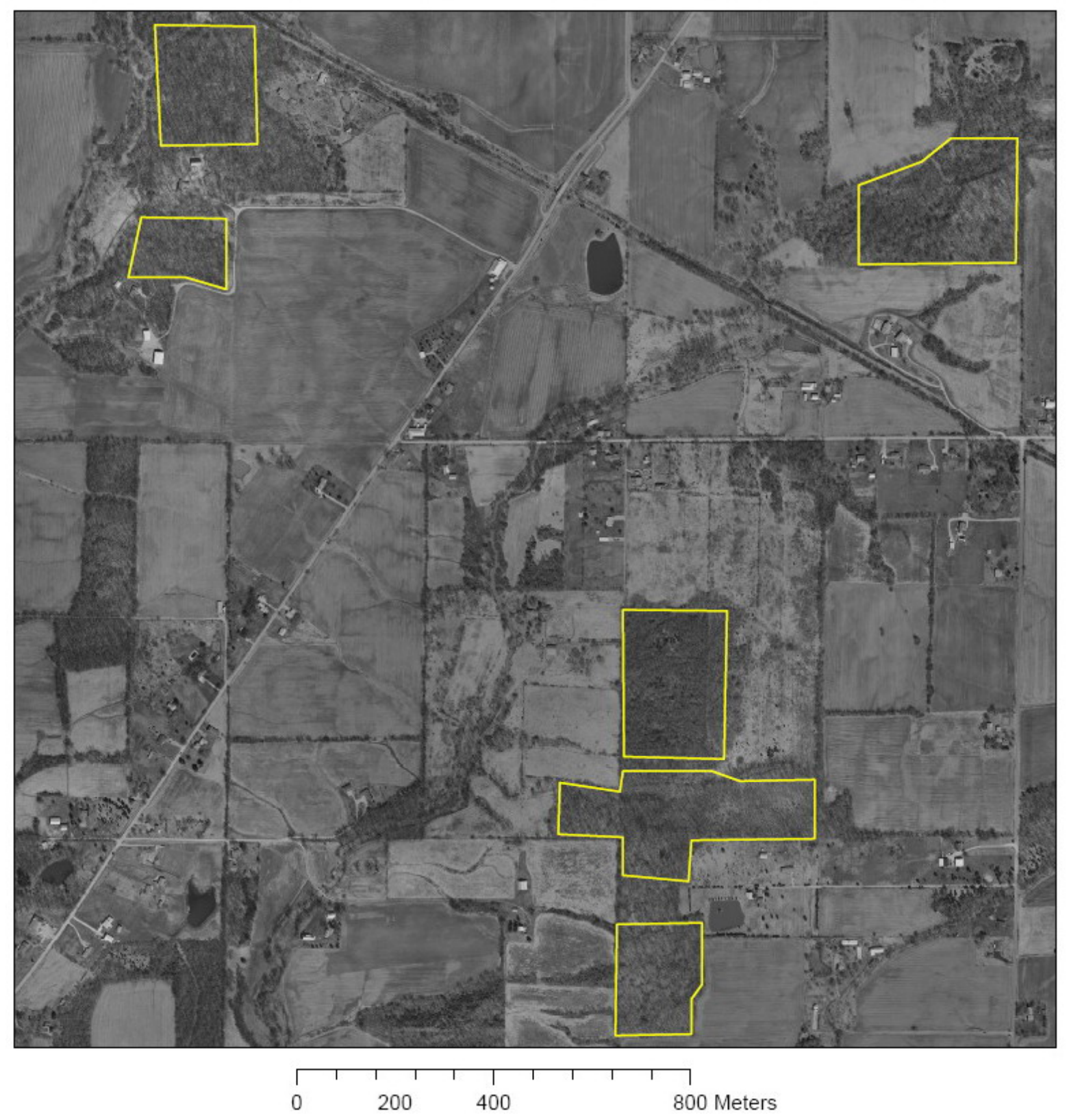


Figure 3 Fall 2006 canopy and shrub layer in sites with high L. maackii abundance (ERC and Kramer) versus sites with no L. maackii presence (Sugarbush and Bigwoods), where solid line is shrub layer and dashed line is canopy.

ERC

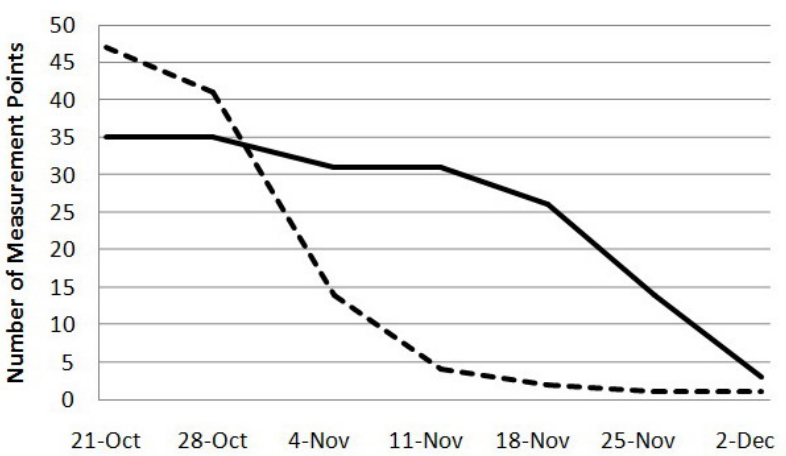

Kramer Woods

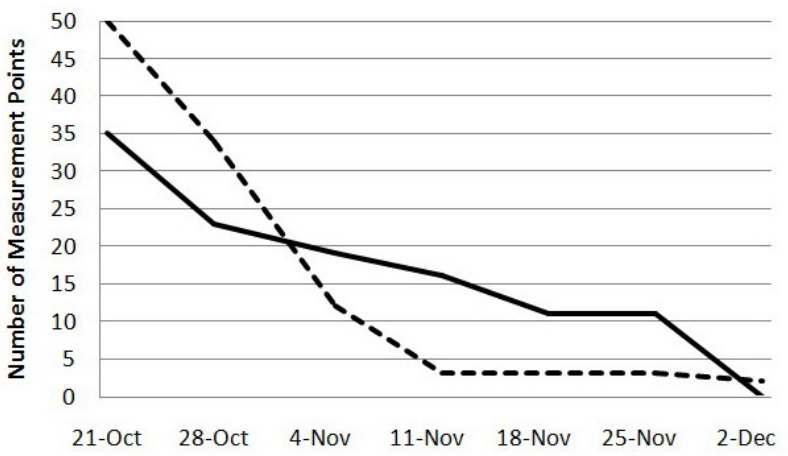

\section{Sugarbush}

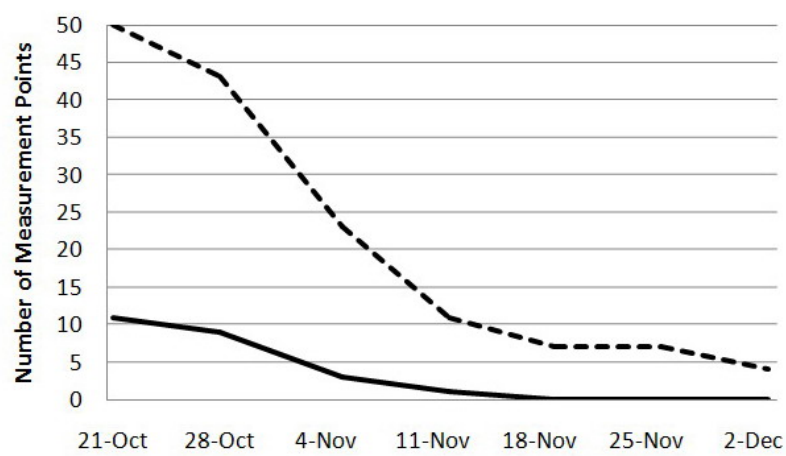

Bigwoods

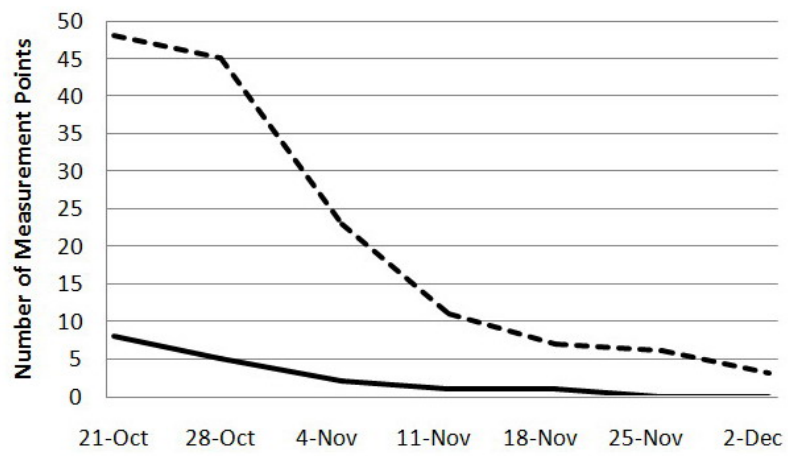


Figure 4 Fall 2007 canopy and shrub layer in sites with high L. maackii abundance (ERC and Kramer) versus sites with no L. maackii presence (Sugarbush and Bigwoods), where solid line is shrub layer and dashed line is canopy.
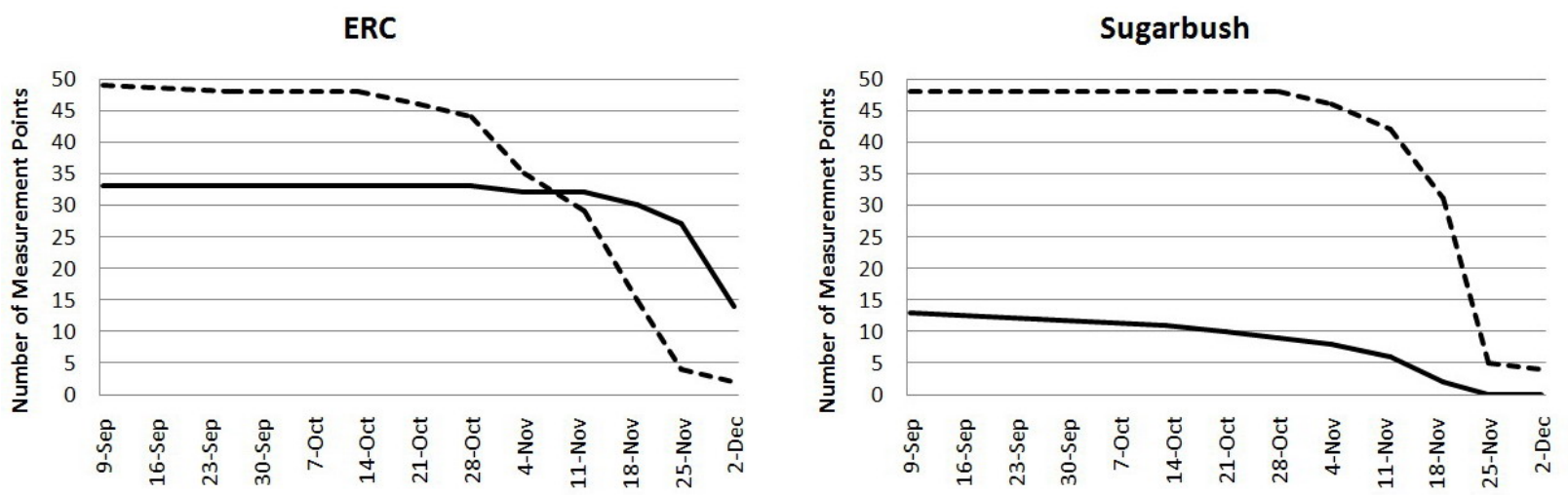

Kramer Woods

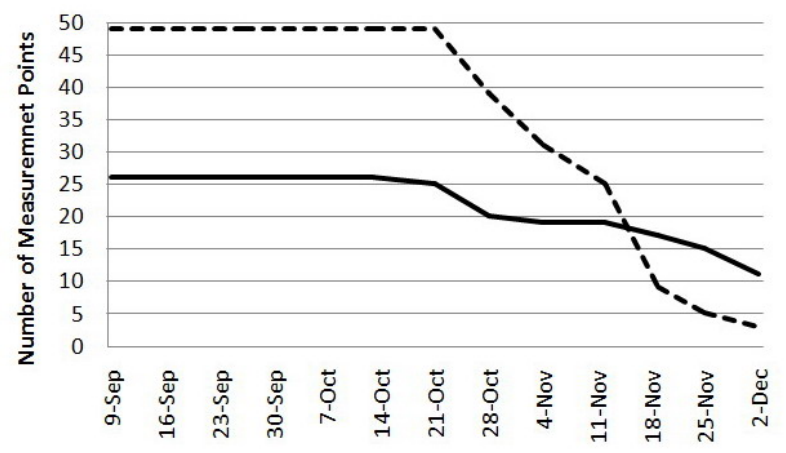

Bigwoods

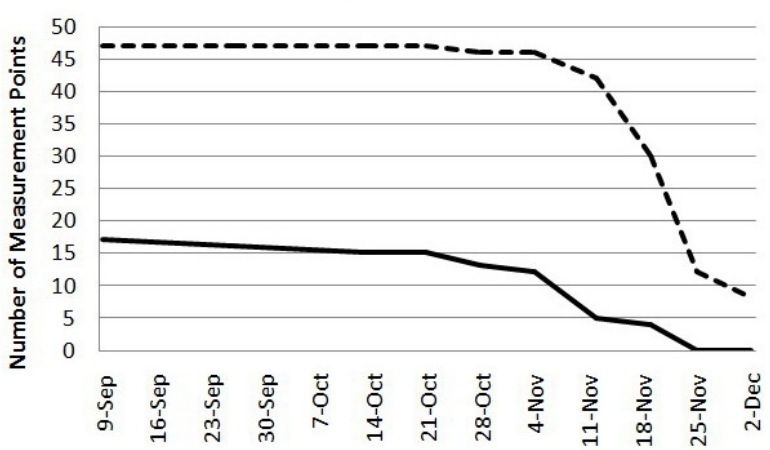


Figure 5 Linear regression of $L$. maackii cover on NDVI of the November 12, 2005 training data. Different color circles distinguish plots with different graminoid cover $($ high $=$ black, medium $=$ gray, and low $=$ white $)$.

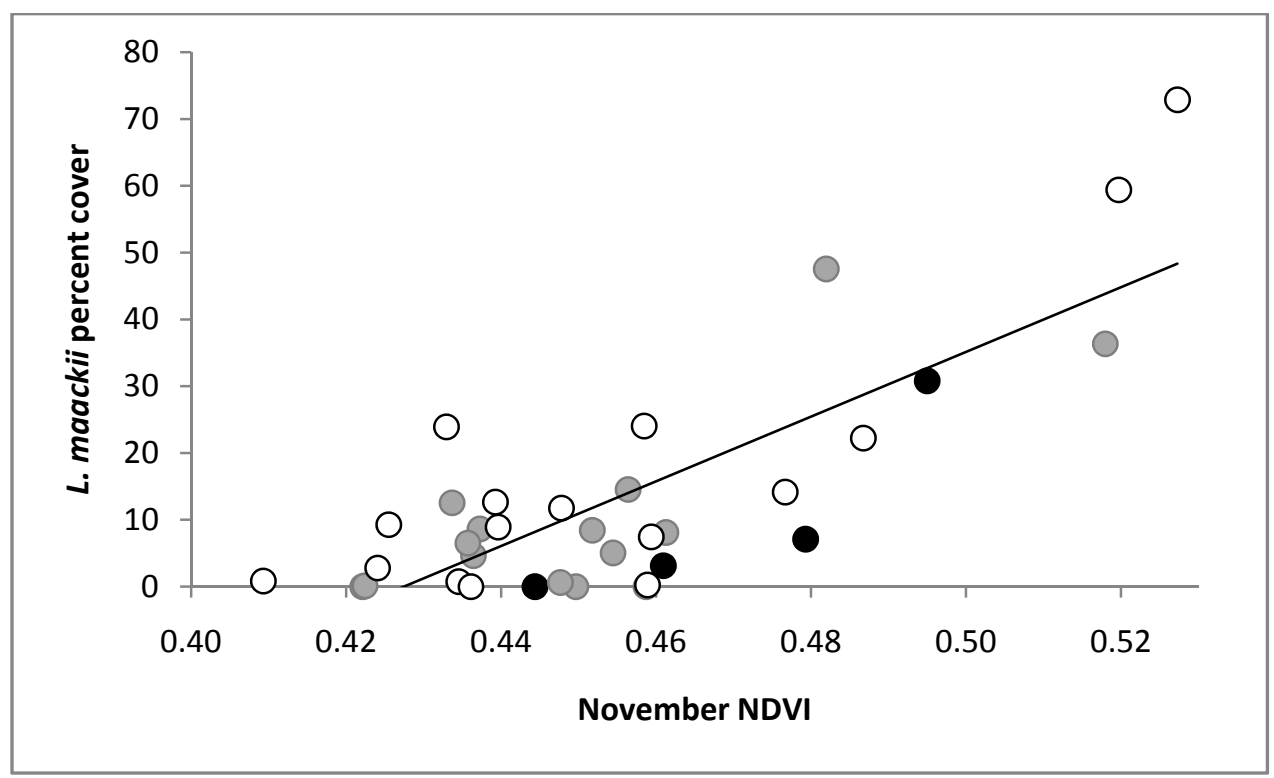

Figure 6 Quadratic polynomial regression of $L$. maackii cover on NDVI of the November 12, 2005 training data. Different color circles distinguish plots with different graminoid cover (high = black, medium = gray, and low $=$ white).

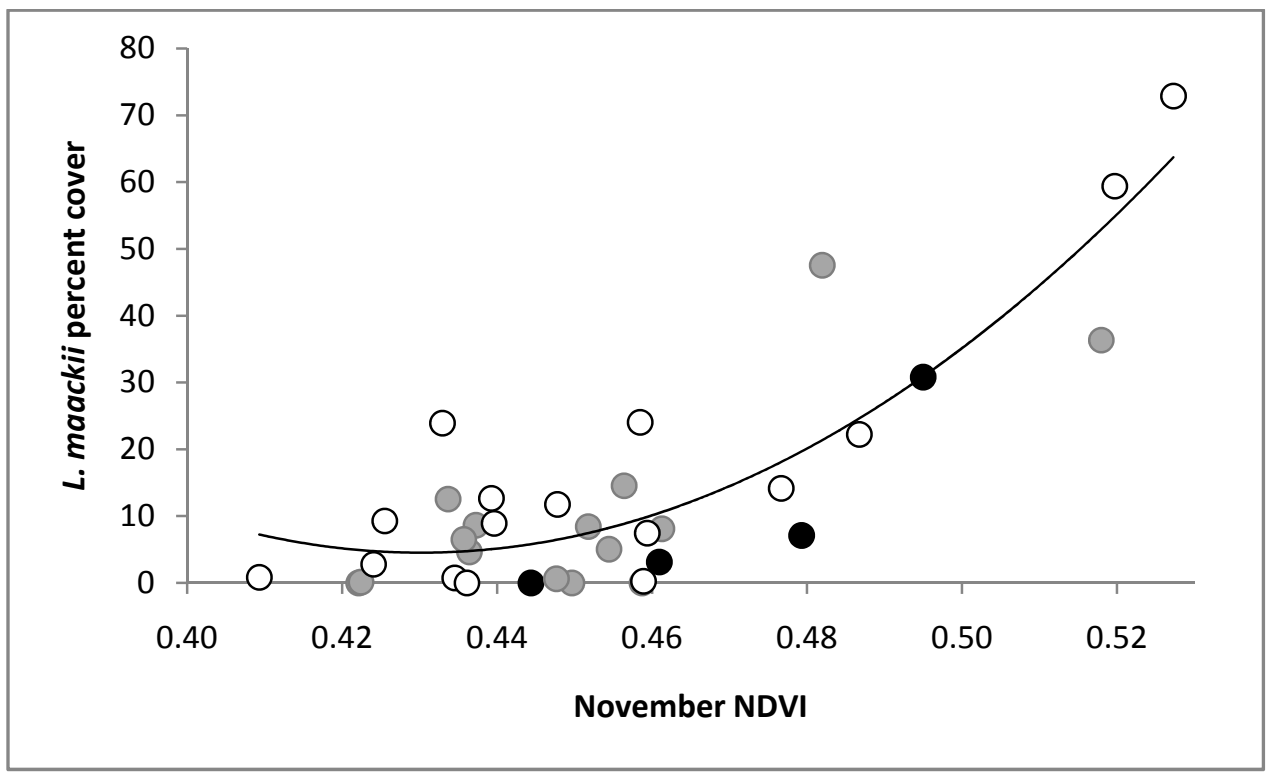


Figure 7 Linear regression of observed $L$. maackii cover on predicted $L$. maackii cover values. Predicted values were calculated from the November verification data using the quadratic polynomial regression model of NDVI. Different color circles distinguish plots with different graminoid cover $($ high $=$ black, medium $=$ gray, and low $=$ white).

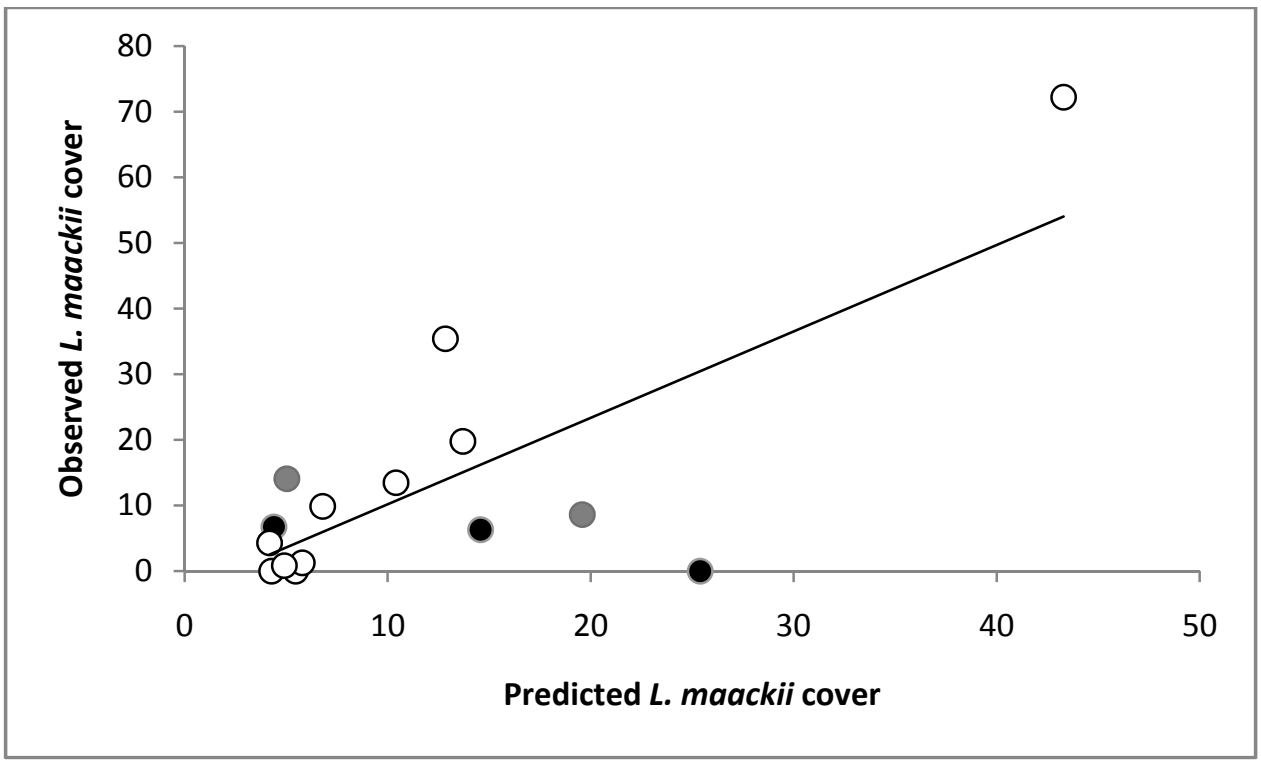

Figure 8 Linear regression of observed $L$. maackii cover on predicted $L$. maackii cover values. Predicted values were calculated from the November 12, 2005 verification data using the linear regression model of NDVI. Different color circles distinguish plots with different graminoid cover $($ high $=$ black, medium $=$ gray, and low $=$ white $)$.

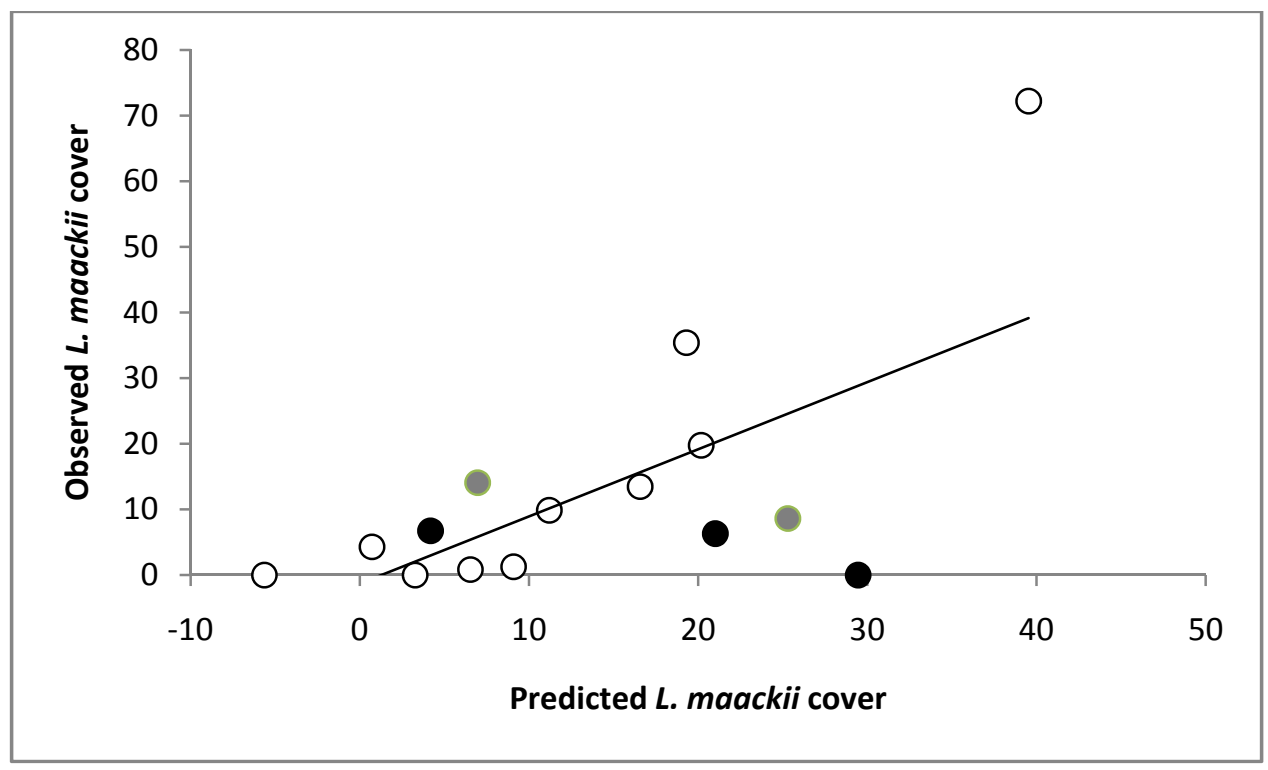


Figure 9 Linear regression of $L$. maackii cover on NDVI using the November training data. Different color circles distinguish plots with differences in disturbance (evident disturbance $=$ black and no apparent disturbance $=$ white).

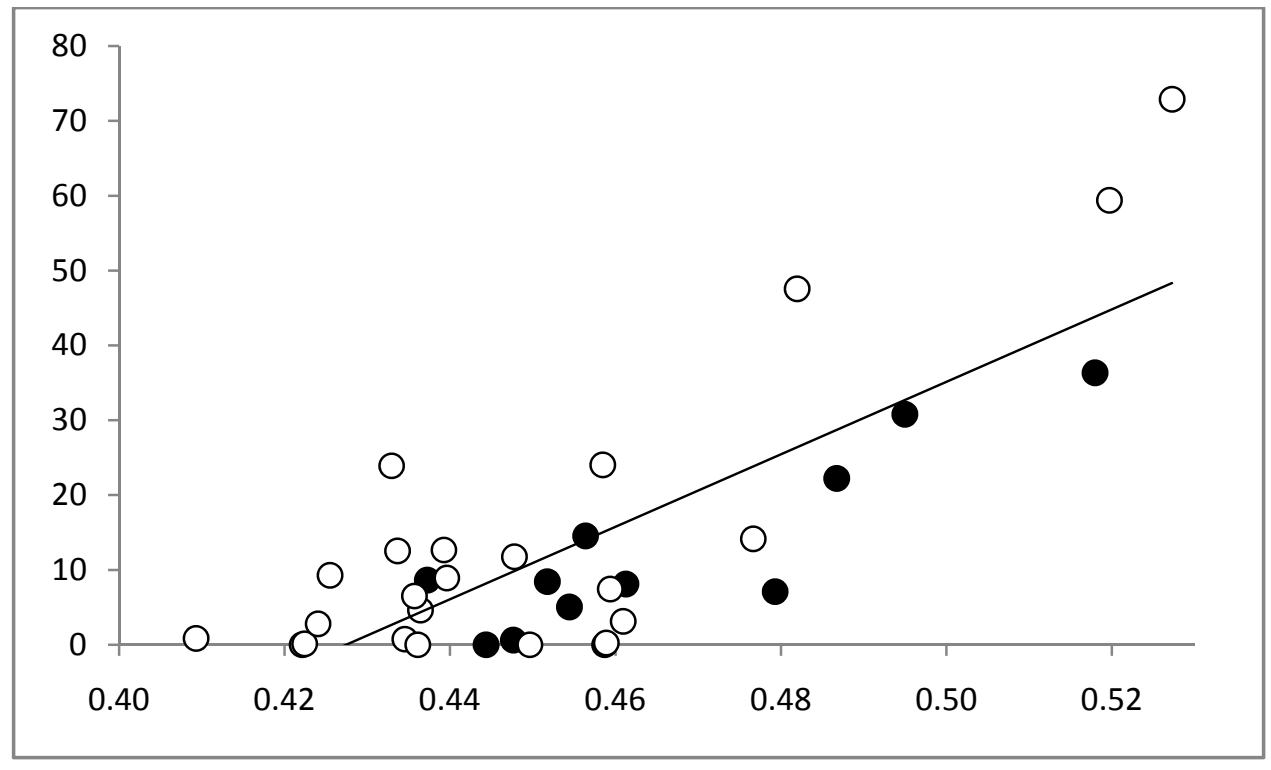

Figure 10 Quadratic regression of $L$. maackii cover on NDVI using the November training data. Different color circles distinguish plots with differences in disturbance (evident disturbance $=$ black and no apparent disturbance $=$ white).

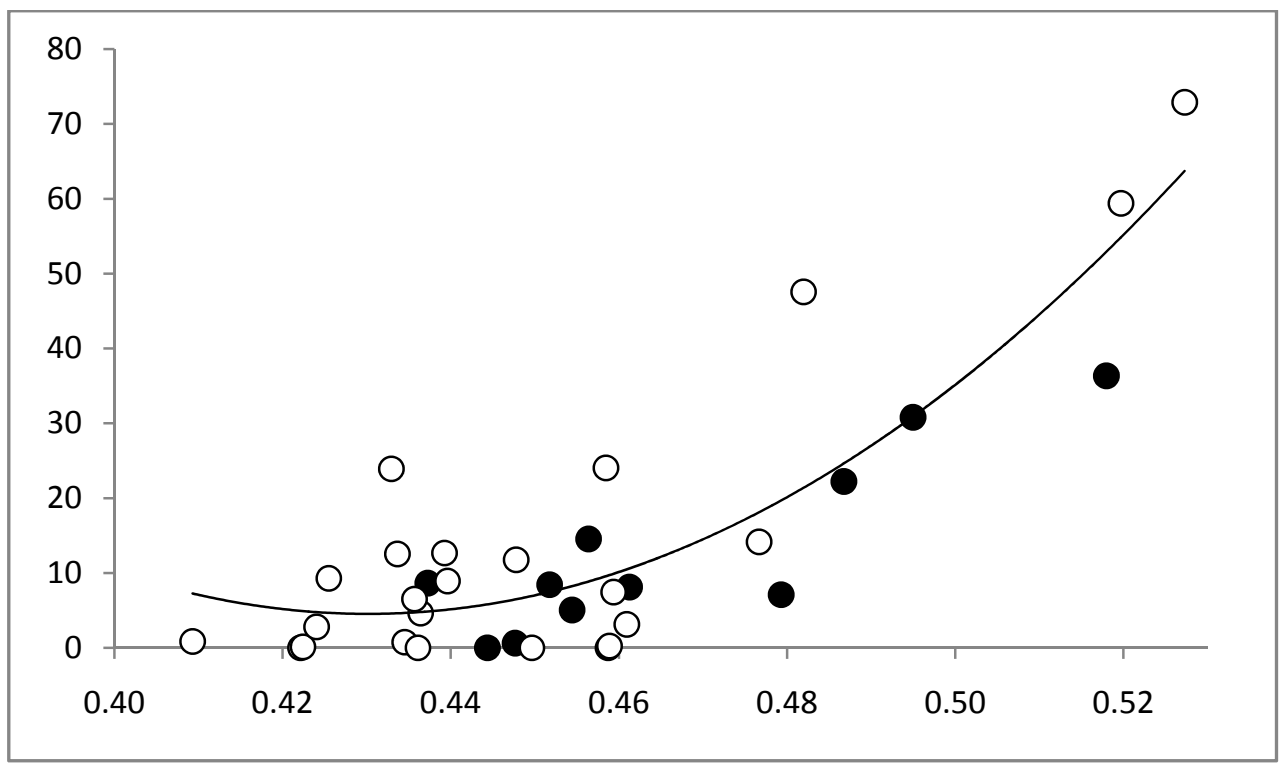


Figure 11 Linear regression of $L$. maackii cover on NDVI using the November training data. Different color circles distinguish between plots with Quercus species and $F$. grandifolia comprising $>20 \%$ of basal area $($ black $=$ high Quercus and F. grandifolia and white = low Quercus and $F$. grandifolia).

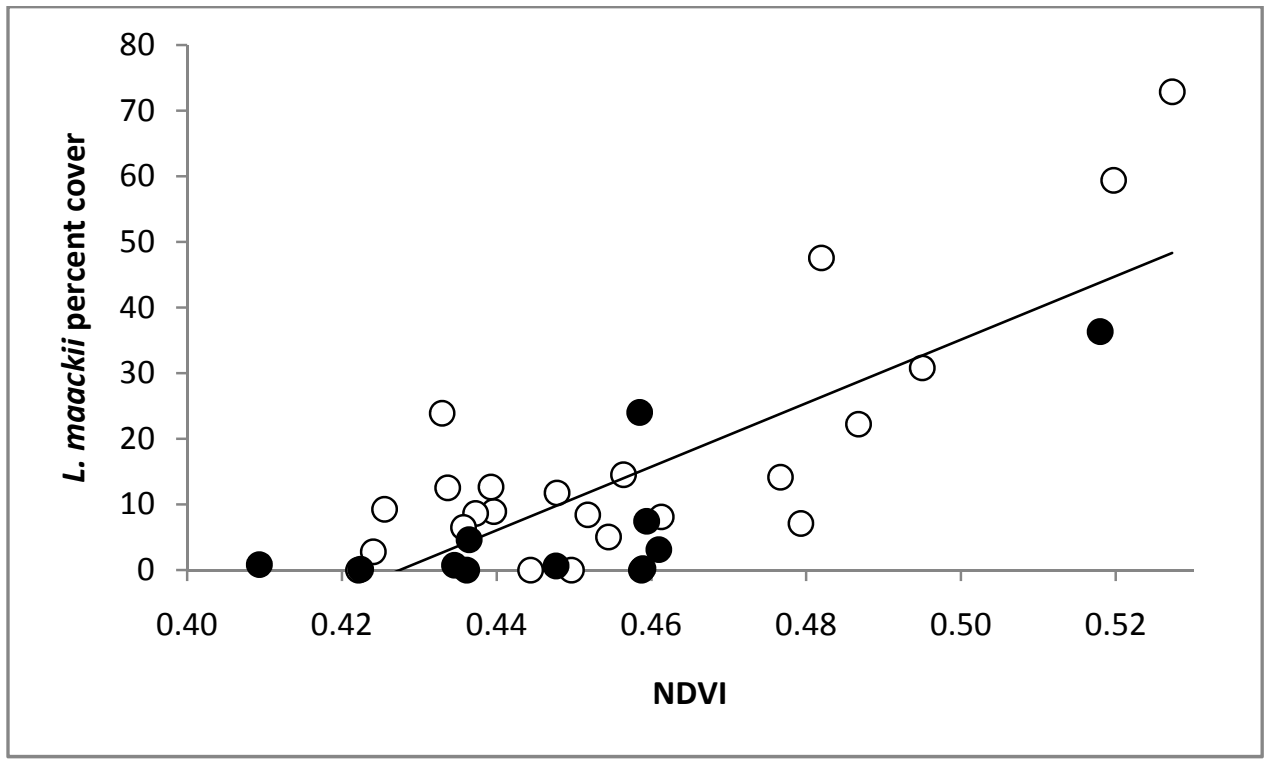

Figure 12 Quadratic regression of $L$. maackii cover on NDVI using the November training data. Different color circles distinguish between plots with Quercus species and $F$. grandifolia comprising $>20 \%$ of basal area $($ black $=$ high Quercus and F. grandifolia and white = low Quercus and $F$. grandifolia).

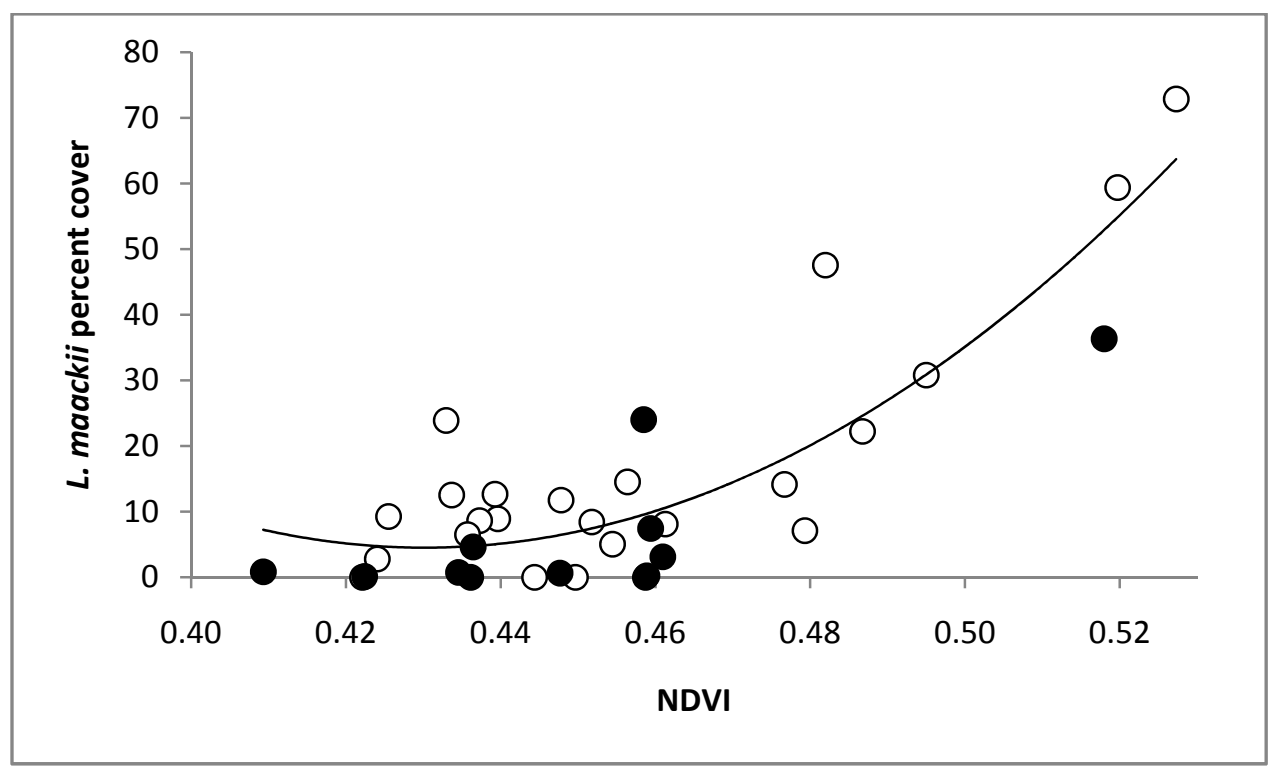




\section{Appendix I}

Correlation tables with Pearson's correlation coefficients and p-values for L. maackii cover, stand density (SD), stand basal area (BA), Normalized Difference Vegetation Index (NDVI), Enhanced Vegetation Index (EVI), Simple Ratio (SR), Tasseled Cap Brightness (TCapB), Tasseled Cap Wetness (TCapW), Tasseled Cap Greenness (TCapG), Visible Atmospherically Resistant Index (VARI), Soil Adjusted Vegetation Index (SAVI), Normalized Difference Moisture Index (NDMI), and reflectance bands $(\mathrm{RB})$ for the training data $(\mathrm{N}=35)$ from the three image dates. 
Table AI-1 Pearson's correlation coefficients and p-values for the January 28, 2002 image.

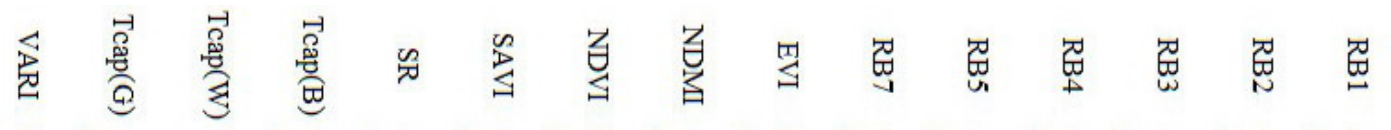

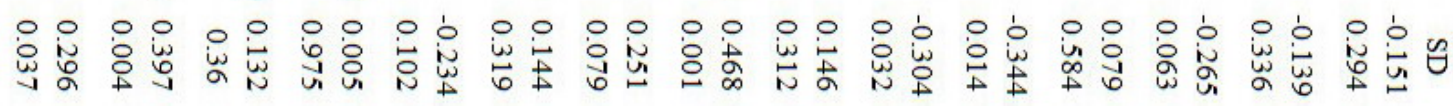

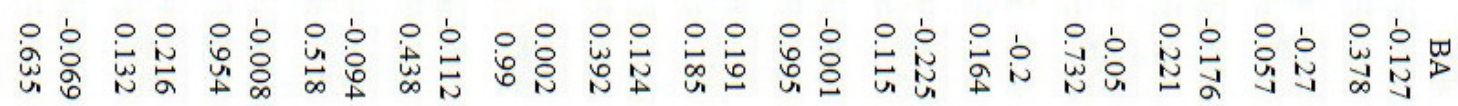

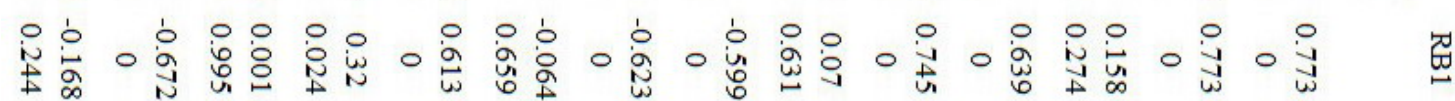

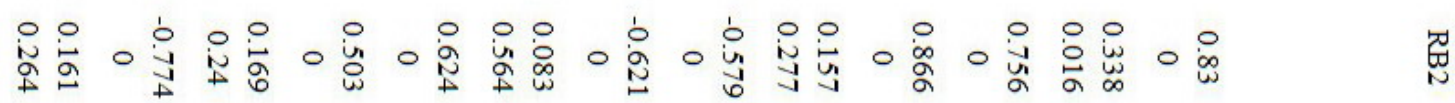

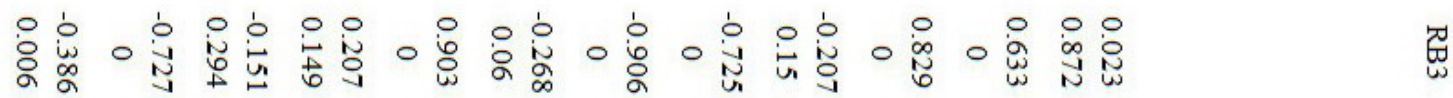

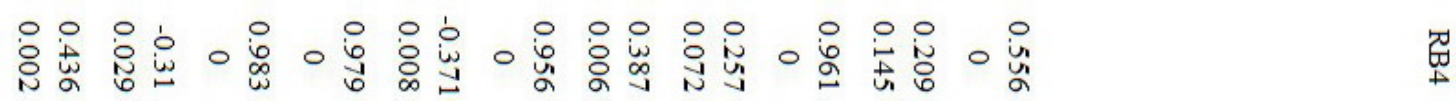

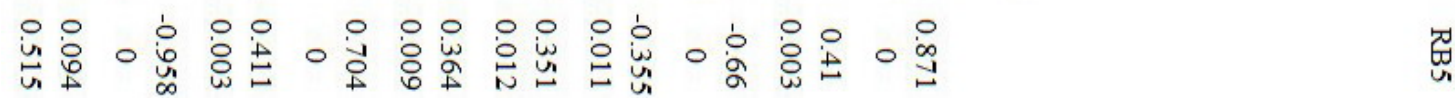

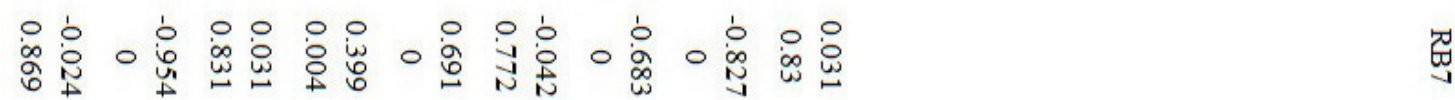

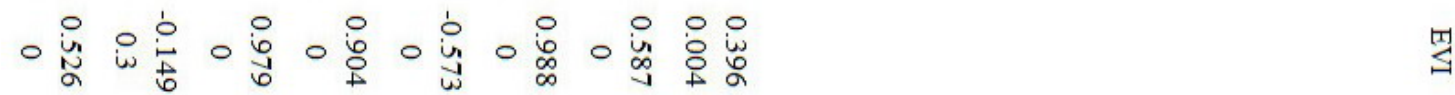

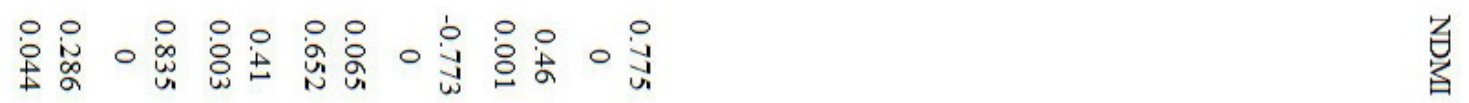

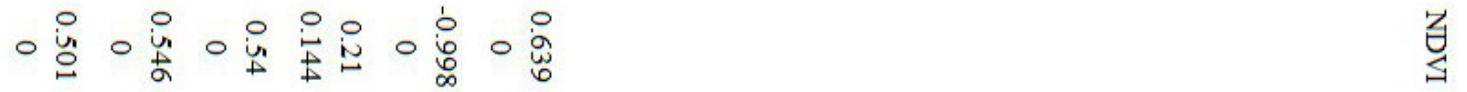

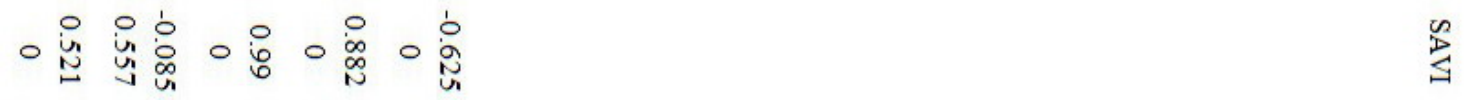

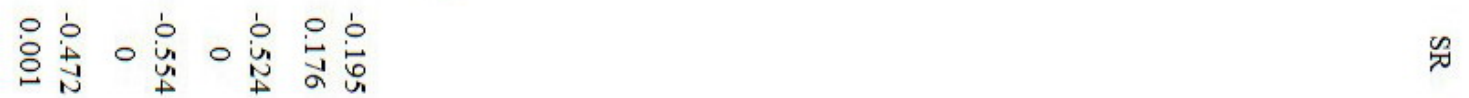

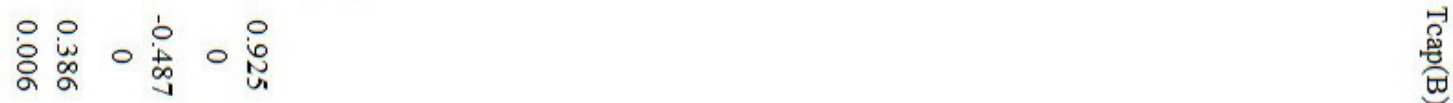

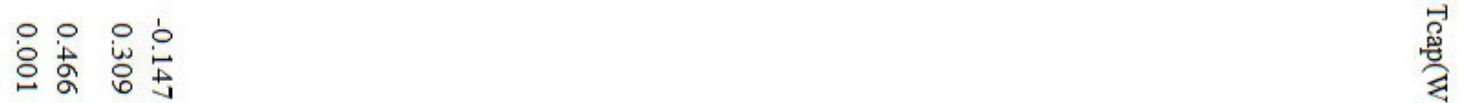

总总总 
Table AI-2 Pearson's correlation coefficients and p-values for the November 12, 2005 Landsat image.

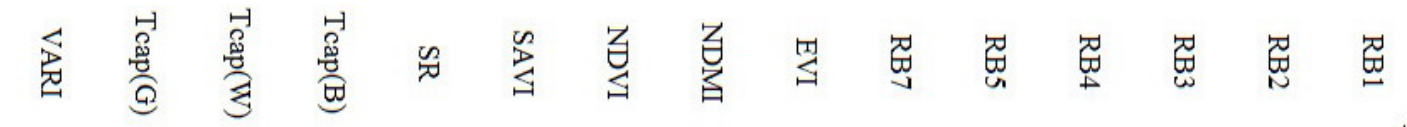

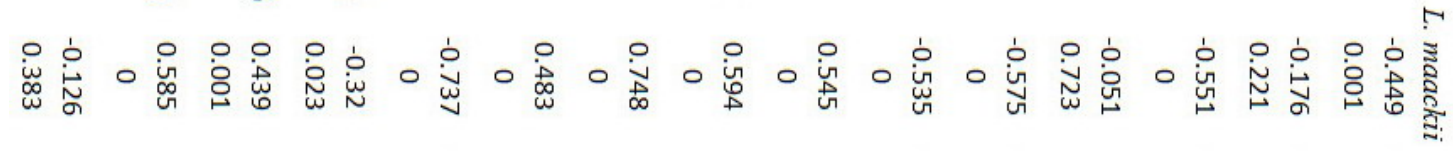

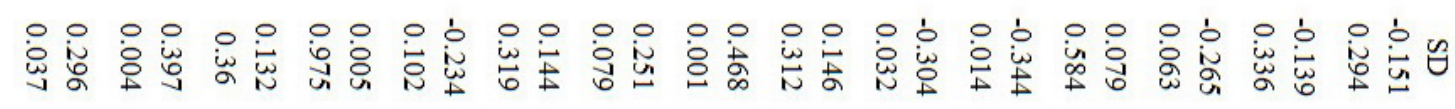

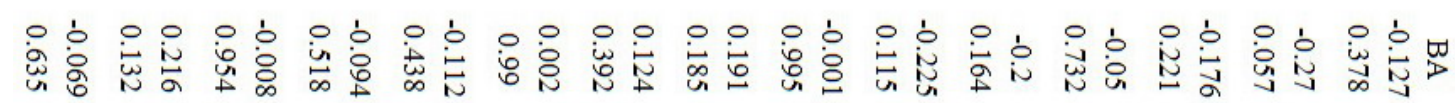

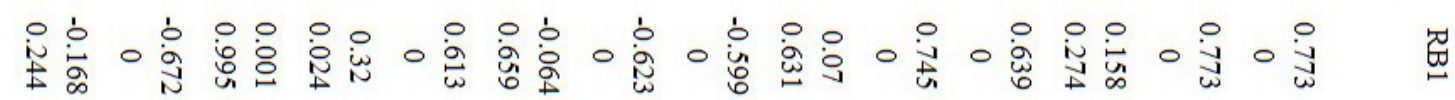

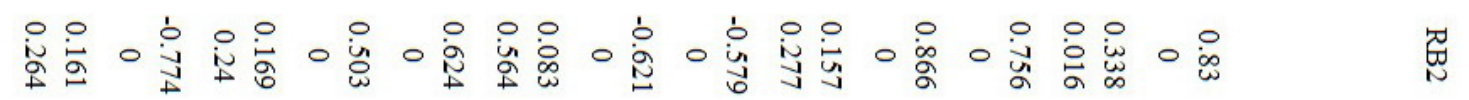

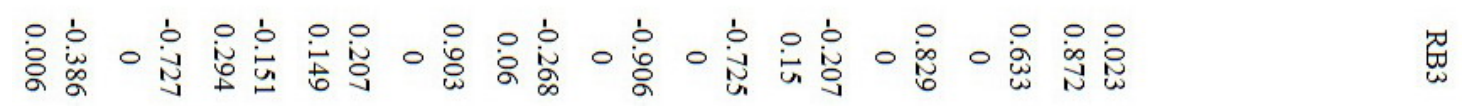

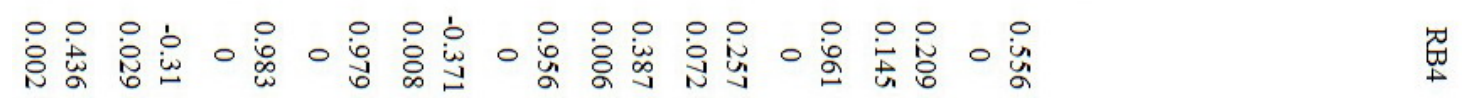

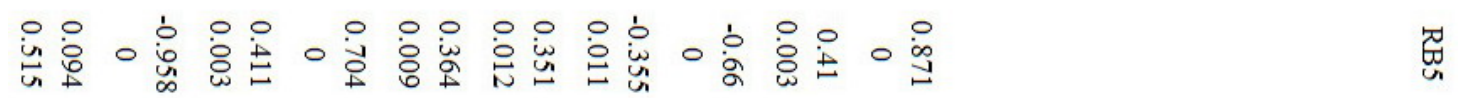

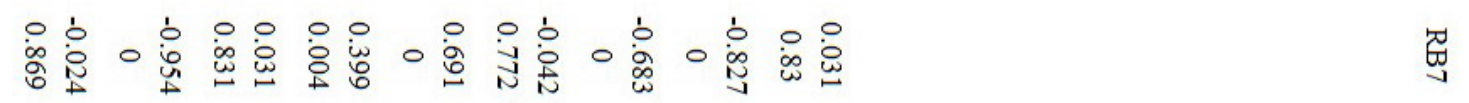
$\circ$ 芯

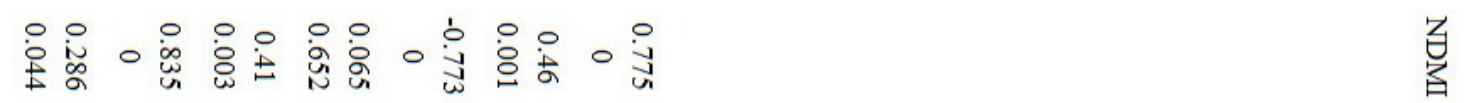

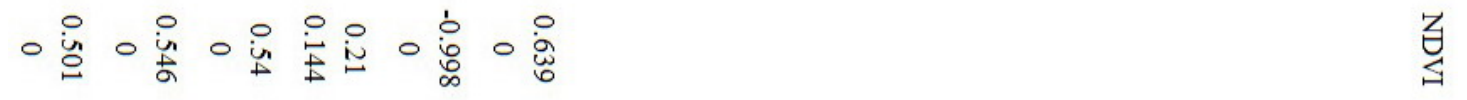

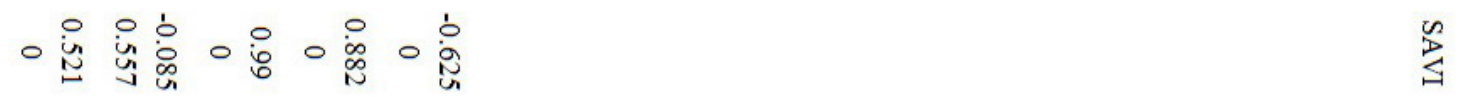

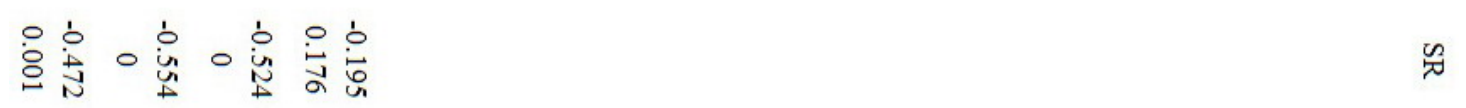

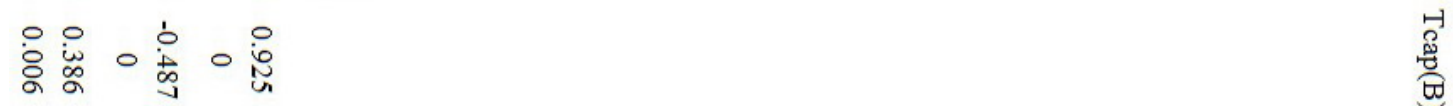

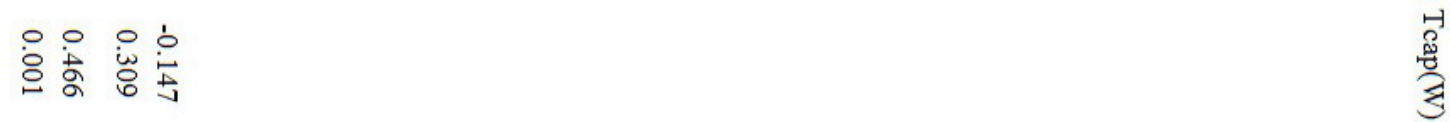
这 
Table AI-3 Pearson's correlation coefficients and p-values for the June 11, 2006 Landsat image.

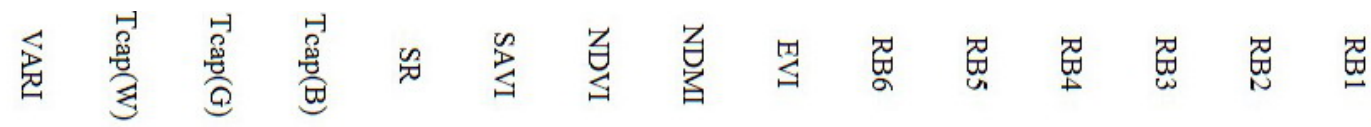

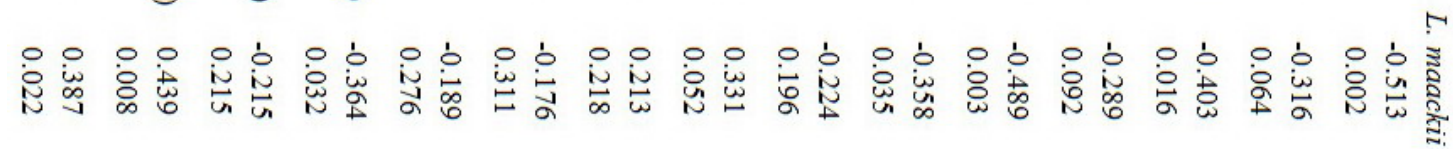

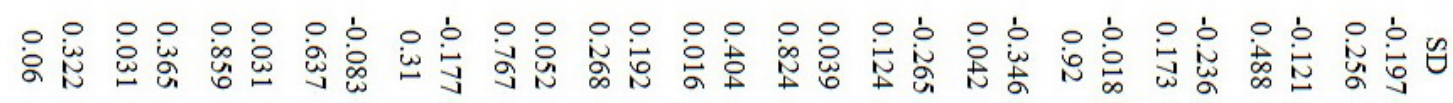

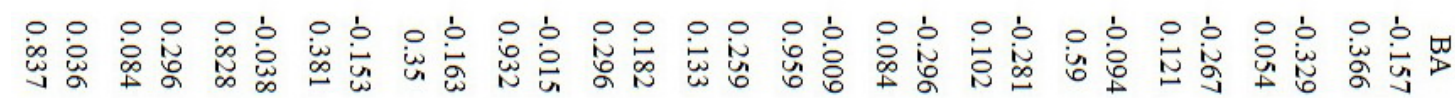

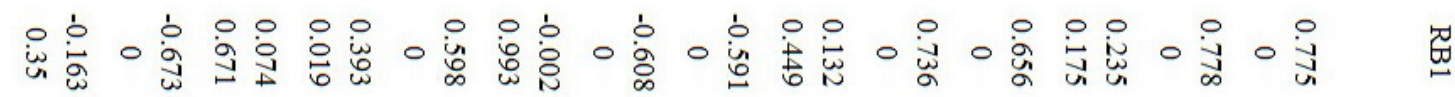
元

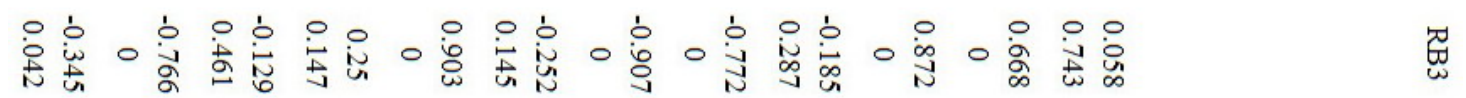

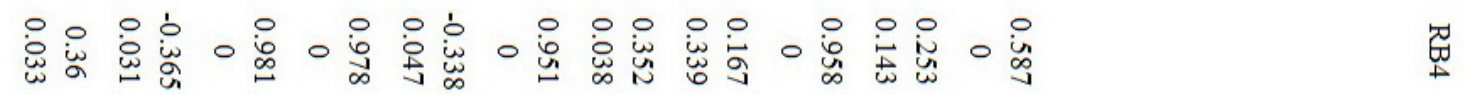

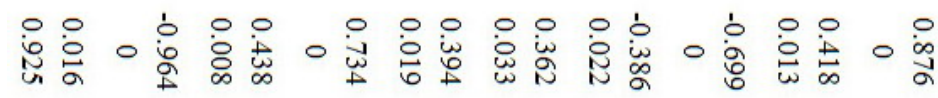

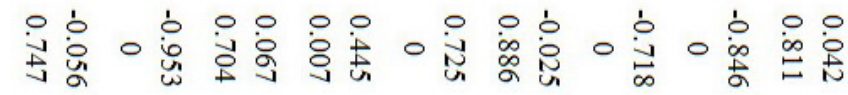

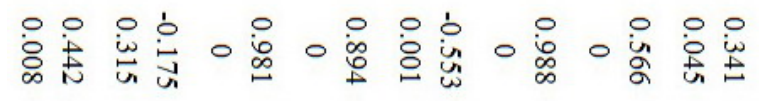

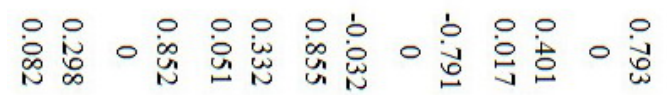

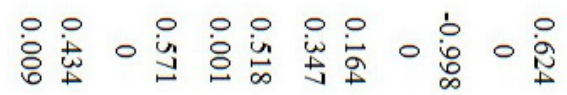

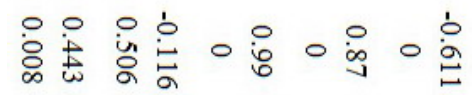

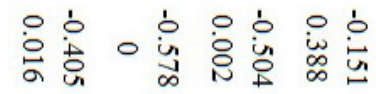

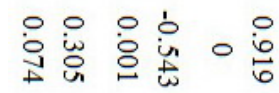

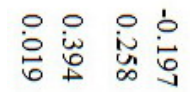

웅요 


\section{Appendix II}

Output from the SAS 9.1 regression analyses for the November 12, 2005 training data.

Table AII-1 Linear regression of $L$. maackii cover on NDVI.

Model: Linear regression

Dependent Variable: L. maackii percent cover

$\begin{array}{ll}\text { Number of Observations Read } & 35 \\ \text { Number of Observations Used } & 35\end{array}$

\begin{tabular}{lrrrrr} 
& \multicolumn{3}{c}{ Analysis of Variance } & & \\
Source & DF & Sum of & Mean & & \\
Model & 1 & 6439.02907 & 6439.02907 & 55.21 & S \\
Error & 33 & 3848.41688 & 116.61869 & & \\
Corrected Total & 34 & 10287 & & &
\end{tabular}

$\begin{array}{llll}\text { Root MSE } & 10.79901 & \text { R-Square } & 0.6259 \\ \text { Dependent Mean } & 13.30129 & \text { Adj R-Sq } & 0.6146 \\ \text { Coeff Var } & 81.18774 & & \end{array}$

\begin{tabular}{llrrrrr}
\multicolumn{7}{c}{ Parameter Estimates } \\
Variable & Label & DF & Parameter & Standard & \\
Intercept & Intercept & 1 & -206.99119 & 29.70265 & -6.97 & $<.0001$ \\
NDVI & NDVI & 1 & 484.22147 & 65.16553 & 7.43 & $<.0001$
\end{tabular}

Table AII-2 Quadratic polynomial regression of $L$. maackii cover on NDVI.

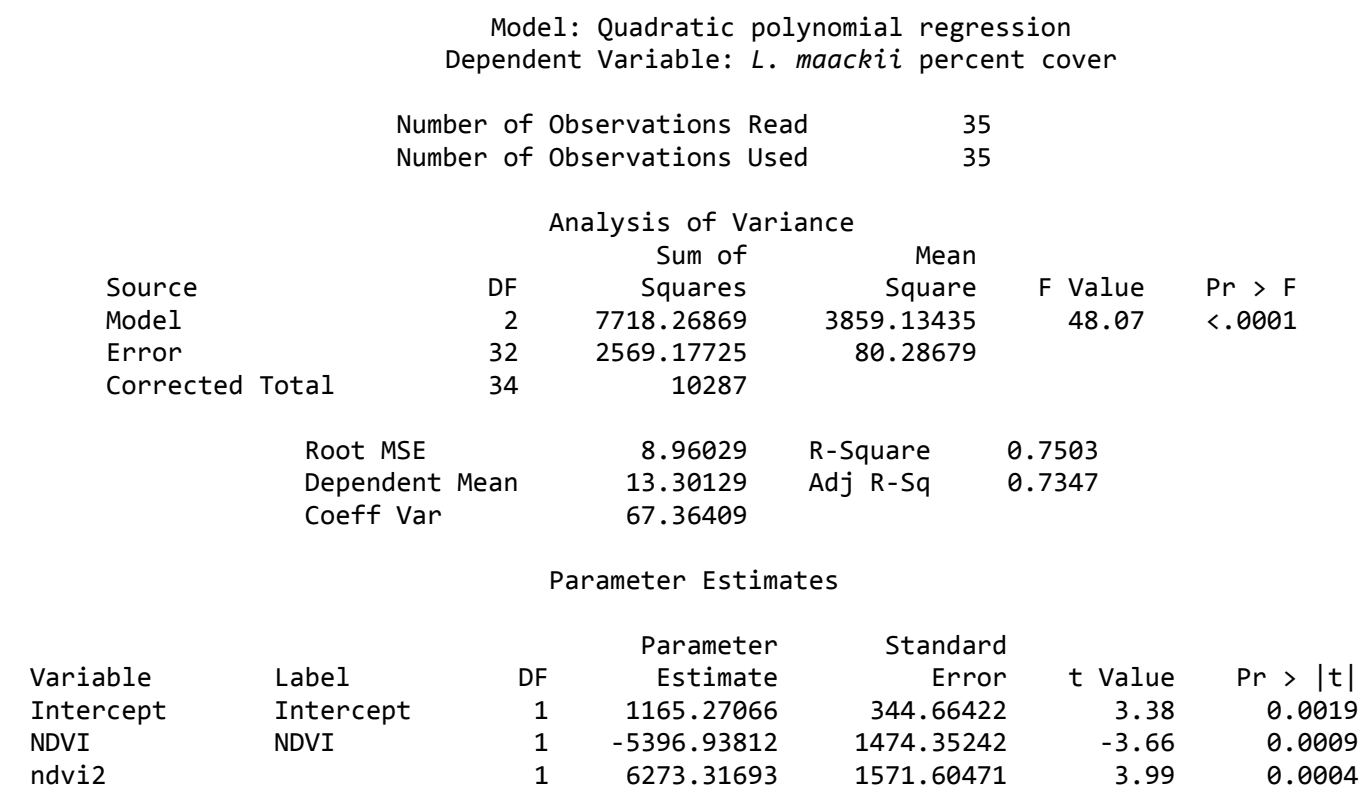




\section{Appendix III}

Information for the ground plots including: data set (Training data $=\mathrm{T}$ and Verification data $=$ V), Lonicera maackii (percent cover), stand basal area (BA) expressed in meters ${ }^{2}$ per hectare, graminoid cover abundance $(\mathrm{H}=$ high, $\mathrm{M}=$ medium, and $\mathrm{L}=$ low), plot disturbance (No disturbance $=0$ and Disturbance $=1$ ), and the $\mathrm{X}, \mathrm{Y}$ coordinate values for plot centers expressed in decimal degrees.

\begin{tabular}{|c|c|c|c|c|c|c|c|}
\hline $\begin{array}{c}\text { Plot } \\
\text { Number }\end{array}$ & Data Set & $\begin{array}{c}\text { Lonicera } \\
\text { maackii }\end{array}$ & $\begin{array}{c}\text { Stand BA } \\
\left(\mathrm{m}^{2} / \mathbf{h a}\right)\end{array}$ & $\begin{array}{c}\text { Graminoid } \\
\text { Cover }\end{array}$ & $\begin{array}{c}\text { Plot } \\
\text { Disturbance }\end{array}$ & $\mathbf{X}$ & $\mathbf{Y}$ \\
\hline 44 & $\mathrm{~T}$ & 0.85 & 24.91 & $\mathrm{~L}$ & 0 & 698424 & 4423380 \\
\hline 46 & $\mathrm{~V}$ & 0 & 22.17 & $\mathrm{~L}$ & 0 & 694422 & 4430820 \\
\hline 55 & V & 8.11 & 32.48 & M & 1 & 695126 & 4432080 \\
\hline 58 & $\mathrm{~T}$ & 0.75 & 38.43 & $\mathrm{~L}$ & 0 & 692450 & 4431340 \\
\hline 124 & $\mathrm{~T}$ & 0 & 27.33 & $\mathrm{~L}$ & 0 & 690982 & 4435300 \\
\hline 129 & $\mathrm{~T}$ & 0 & 28.08 & $\mathrm{M}$ & 0 & 689348 & 4436790 \\
\hline 137 & $\mathrm{~V}$ & 6.75 & 27.16 & $\mathrm{H}$ & 1 & 702818 & 4429950 \\
\hline 143 & $\mathrm{~T}$ & 0 & 21.08 & $\mathrm{H}$ & 1 & 686369 & 4402220 \\
\hline 314 & $\mathrm{~T}$ & 30.81 & 14.40 & $\mathrm{H}$ & 1 & 692085 & 4423630 \\
\hline 332 & V & 0 & 31.01 & $\mathrm{~L}$ & 0 & 693862 & 4428400 \\
\hline 352 & $\mathrm{~T}$ & 0 & 25.13 & $\mathrm{M}$ & 1 & 692598 & 4406130 \\
\hline 456 & $\mathrm{~V}$ & 24.04 & 25.50 & $\mathrm{~L}$ & 0 & 705165 & 4425450 \\
\hline 464 & $\mathrm{~V}$ & 0.13 & 15.60 & $M$ & 0 & 698029 & 4424590 \\
\hline 470 & $\mathrm{~T}$ & 11.76 & 25.18 & $\mathrm{~L}$ & 0 & 692056 & 4423080 \\
\hline 480 & $\mathrm{~V}$ & 7.10 & 29.13 & $\mathrm{H}$ & 1 & 690533 & 4424150 \\
\hline 498 & $\mathrm{~V}$ & 1.27 & 20.65 & $\mathrm{~L}$ & 0 & 691637 & 4425080 \\
\hline 510 & $\mathrm{~T}$ & 2.79 & 2.91 & $\mathrm{~L}$ & 0 & 696183 & 4423350 \\
\hline 515 & $\mathrm{~V}$ & 6.32 & 38.71 & $\mathrm{H}$ & 1 & 694556 & 4389840 \\
\hline 516 & $\mathrm{~T}$ & 3.13 & 36.14 & $\mathrm{H}$ & 0 & 689581 & 4405020 \\
\hline 517 & $\mathrm{~T}$ & 9.28 & 28.97 & $\mathrm{~L}$ & 0 & 690817 & 4408330 \\
\hline 519 & $\mathrm{~T}$ & 14.15 & 11.89 & $\mathrm{~L}$ & 0 & 695430 & 4424330 \\
\hline 610 & $\mathrm{~T}$ & 0 & 27.75 & $M$ & 0 & 691704 & 4427260 \\
\hline $119 \mathrm{P}$ & $\mathrm{T}$ & 59.40 & 55.63 & $\mathrm{~L}$ & 0 & 696105 & 4432960 \\
\hline $128 \mathrm{ps}$ & $\mathrm{T}$ & 72.90 & 18.70 & $\mathrm{~L}$ & 0 & 692536 & 4428380 \\
\hline $269-270$ & V & 14.08 & 15.93 & M & 1 & 687633 & 4407440 \\
\hline $279 p$ & $\mathrm{~T}$ & 8.43 & 26.87 & $M$ & 1 & 693747 & 4427360 \\
\hline $28 \mathrm{ps}$ & $\mathrm{T}$ & 8.92 & 28.93 & $\mathrm{~L}$ & 0 & 700748 & 4407440 \\
\hline $361 p$ & $\mathrm{~T}$ & 0.63 & 22.16 & $M$ & 1 & 693841 & 4423830 \\
\hline $366 p$ & $\mathrm{~T}$ & 8.61 & 44.75 & M & 1 & 691571 & 4408980 \\
\hline $374 p$ & $\mathrm{~T}$ & 12.67 & 25.19 & $\mathrm{~L}$ & 0 & 696998 & 4397940 \\
\hline $377 p$ & $\mathrm{~T}$ & 22.24 & 33.16 & $M$ & 1 & 696353 & 4425780 \\
\hline $378 \mathrm{p}$ & $\mathrm{T}$ & 23.92 & 32.52 & $\mathrm{~L}$ & 0 & 692563 & 4397730 \\
\hline $379 p$ & $\mathrm{~T}$ & 7.44 & 30.94 & $\mathrm{~L}$ & 0 & 692596 & 4425520 \\
\hline $380 \mathrm{p}$ & $\mathrm{V}$ & 35.41 & 31.74 & $\mathrm{~L}$ & 0 & 689199 & 4406770 \\
\hline
\end{tabular}




\begin{tabular}{|c|c|c|c|c|c|c|c|}
\hline $\begin{array}{c}\text { Plot } \\
\text { Number }\end{array}$ & $\begin{array}{c}\text { Plot } \\
\text { Division }\end{array}$ & $\begin{array}{c}\text { Lonicera } \\
\text { maackii }\end{array}$ & $\begin{array}{c}\text { Stand BA } \\
\left(\mathbf{m}^{\mathbf{2}} / \mathbf{h a}\right)\end{array}$ & $\begin{array}{c}\text { Graminoid } \\
\text { Cover }\end{array}$ & $\begin{array}{c}\text { Plot } \\
\text { Disturbance }\end{array}$ & $\mathbf{X}$ & $\mathbf{Y}$ \\
\hline $382 \mathrm{p}$ & $\mathrm{T}$ & 12.55 & 15.89 & $\mathrm{M}$ & 0 & 687308 & 4410150 \\
\hline $383 \mathrm{p}$ & $\mathrm{T}$ & 4.64 & 18.25 & $\mathrm{M}$ & 0 & 693393 & 4395600 \\
\hline $387 \mathrm{p}$ & $\mathrm{T}$ & 5.05 & 42.76 & $\mathrm{M}$ & 1 & 699514 & 4434560 \\
\hline $3 \mathrm{i}$ & $\mathrm{V}$ & 0 & 25.06 & $\mathrm{H}$ & 0 & 694676 & 4428370 \\
\hline $453-454$ & $\mathrm{~V}$ & 8.63 & 31.29 & $\mathrm{M}$ & 0 & 693008 & 4396940 \\
\hline $457-458$ & $\mathrm{~V}$ & 0.85 & 11.43 & $\mathrm{~L}$ & 0 & 692398 & 4425920 \\
\hline $475-476$ & $\mathrm{~V}$ & 19.78 & 27.69 & $\mathrm{~L}$ & 0 & 688405 & 4408980 \\
\hline $478-479$ & $\mathrm{~T}$ & 6.54 & 12.39 & $\mathrm{M}$ & 0 & 687860 & 4408880 \\
\hline $50-51 \mathrm{ps}$ & $\mathrm{T}$ & 14.55 & 32.90 & $\mathrm{M}$ & 1 & 693910 & 4423490 \\
\hline $511-512$ & $\mathrm{~T}$ & 36.35 & 22.17 & $\mathrm{M}$ & 1 & 692750 & 4433830 \\
\hline $513-514$ & $\mathrm{~V}$ & 72.22 & 21.68 & $\mathrm{~L}$ & 1 & 689474 & 4407450 \\
\hline $525-526$ & $\mathrm{~T}$ & 0.24 & 30.27 & $\mathrm{~L}$ & 0 & 694615 & 4425200 \\
\hline $52 \mathrm{ps}$ & $\mathrm{V}$ & 9.88 & 27.70 & $\mathrm{~L}$ & 0 & 681691 & 4400930 \\
\hline $5 \mathrm{i}$ & $\mathrm{T}$ & 47.57 & 31.49 & $\mathrm{M}$ & 0 & 687921 & 4414070 \\
\hline $66 \mathrm{ps}$ & $\mathrm{V}$ & 13.48 & 46.53 & $\mathrm{~L}$ & 0 & 694345 & 4424980 \\
\hline $144 \mathrm{ps}$ & $\mathrm{V}$ & 4.31 & 32.78 & $\mathrm{~L}$ & 0 & 699935 & 4391220 \\
\hline
\end{tabular}

